\author{
UNIVERSIDADE DE SÃO PAULO \\ FACULDADE DE MEDICINA DE RIBEIRÃO PRETO \\ PROGRAMA DE PÓS-GRADUAÇÃO EM FISIOLOGIA
}

\title{
Alterações cardiovasculares e respiratórias em ratas submetidas à hipóxia crônica intermitente
}

GEORGE MIGUEL P. R. SOUZA

Ribeirão Preto 
GEORGE MIGUEL P. R. SOUZA

\title{
Alterações cardiovasculares e respiratórias em ratas submetidas à hipóxia crônica intermitente
}

\author{
Dissertação de mestrado \\ apresentada ao Programa de Pós- \\ graduação em Fisiologia da \\ Faculdade de Medicina de \\ Ribeirão Preto, Universidade de \\ São Paulo, para a obtenção de \\ título de mestre em ciências.
}

Área de concentração: Fisiologia

Orientador: Prof. Dr. Benedito H. Machado 


\section{FICHA CATALOGRÁFICA}

Autorizo a reprodução e divulgação total ou parcial deste trabalho, por qualquer meio convencional ou eletrônico, para fins de estudo e pesquisa, desde que citada a fonte.

Souza, George Miguel Perbone Robuste

Alterações cardiovasculares e respiratórias em ratas submetidas à hipóxia crônica intermitente.

77 p.: il.; $30 \mathrm{~cm}$

Dissertação de Mestrado, apresentada à Faculdade de Medicina de Ribeirão Preto/USP. Área de concentração: Fisiologia.

Orientador: Machado, Benedito H.

1. Hipertensão arterial 2. Hipóxia Crônica Intermitente 3. Acoplamento Simpático-Respiratório 4. Fêmeas 


\section{FOLHA DE APROVAÇÃO}

Aluno: George Miguel Perbone Robuste Souza

Título: Alterações cardiovasculares e respiratórias em ratas submetidas à hipóxia crônica intermitente.

Dissertação de mestrado apresentada ao

Programa de Pós-graduação em Fisiologia da Faculdade de Medicina de Ribeirão Preto, Universidade de São Paulo, para obtenção do título de Mestre. Área de concentração: Fisiologia

Aprovado em:

\section{Banca examinadora}

\section{Prof. Dr. Celso Rodrigues Franci}

Instituição: Departamento de Fisiologia, Faculdade de Medicina de Ribeirão Preto, USP.

Assinatura:

\section{Prof. Dr. Sérgio Luiz Domingues Cravo}

Instituição: Departamento de Fisiologia, Escola Paulista de Medicina, UNIFESP. Assinatura:

\section{Prof. Dr. Benedito H. Machado}

Instituição: Departamento de Fisiologia, Faculdade de Medicina de Ribeirão Preto, USP.

Assinatura: 
Dedico esta dissertação à minha família: Maria Robuste, João Perbone, Geralda Ramos, Marco Aurélio e João Carlos. 


\section{AGRADECIMENTOS}

- à minha mãe Maria Robuste, ao meu pai João Perbone, meus irmãos Marco Aurélio e João Carlos e a minha avó, Geralda Ramos pela confiança, pelas palavras de apoio durante essa e todas as jornadas de minha vida. Obrigado pelo seu bom humor e otimismo, que me ajudaram muito. Agradeço muito pelo seu apoio, carinho e amor incondicional, que dão sentido a tudo que faço. É impossível dizer apenas com palavras o quanto eu sou grato a vocês. Muito Obrigado!

- à Joyce Ioshida, que foi uma amiga e companheira durante todos os dias desde que comecei o Mestrado. Agradeço por me escutar e me aconselhar sempre que foi necessário, tornando mais fácil esta jornada. Obrigado pelo seu carinho, paciência e amor que fizeram toda a diferença para mim durante este período. Obrigado por ser quem você é!

- ao professor Dr. Benedito H. Machado que me recebeu em seu laboratório e criou todas as condições e oportunidades possíveis para a realização desta dissertação e para a minha formação. Obrigado pela confiança e incentivo em todos os momentos desde que cheguei ao laboratório. Gostaria de agradecer também pela orientação objetiva e a enorme atenção aos meus textos, às minhas apresentações e aos experimentos. Um exemplo de professor atencioso e de um cientista dedicado ao qual pretendo seguir durante toda a minha carreira.

- à Leni Bonagamba, que me ensinou que fazer experimentos é mais do que uma rotina, mas também uma arte. Obrigado por me ensinar que devemos ser perfeccionistas e que a experiência profissional é a melhor escola. Obrigado por me ajudar a organizar não apenas os experimentos, mas também grande parte de minhas ideias!

- à Davi Moraes, que além de um grande amigo, foi também um professor. Obrigado pelos ensinamentos com os experimentos envolvendo a preparação coração troncocerebral isolados e por nossas discussões sobre fisiologia celular e integrativa. Obrigado 
por sempre estar disposto a ajudar e a discutir os nossos resultados e dúvidas. A sua empolgação e motivação pela ciência são um exemplo para mim.

- à Mateus Amorim, que foi um amigo dentro e fora do laboratório, com um bom humor que é essencial no dia-a-dia. É um exemplo de que, além da formação pessoal, na pósgraduação podemos encontrar grandes amigos.

- aos meus amigos de laboratório Kauê, Cadu, Ludmila, Andressa e especialmente, a Marlusa Amarante, Daniela Acorssi-Mendonça e Raphael Perim pelas intensas discussões, por cultivarem um ambiente agradável no laboratório e por sempre estarem dispostos a me ajudar com qualquer dúvida, com qualquer explicação. Obrigado pelos seus ensinamentos e pela sua amizade e por constituírem uma equipe de laboratório admirável!

- ao Prof. Dr. Celso R. Franci por ter cedido gentilmente o seu laboratório para as dosagens hormonais e pelas intensas discussões sobre fisiologia neuroendócrina.

- aos meus amigos do Departamento que contribuíram com discussões, ideias, e até mesmo com os experimentos. Agradeço especialmente ao Carlos Alberto (Beto) e ao André Mecawi pela ajuda com os experimentos envolvendo o animal acordado.

- à Cláudia, Elisa e Fernando da secretária do Departamento de Fisiologia por prestarem um serviço se excelente qualidade e por sempre estarem dispostos a ajudar. 
Este trabalho foi desenvolvido com o apoio financeiro da CAPES, CNPq e FAPESP. 
"A coisa mais bela que podemos experimentar é o mistério. Essa é a fonte de toda arte e ciências verdadeiras.” Albert Einstein 


\section{RESUMO}

\section{SOUZA, G.M.P.R. Alterações cardiovasculares e respiratórias em ratas submetidas}

à hipóxia crônica intermitente. 77 p. Dissertação (Mestrado) - Faculdade de Medicina de Ribeirão Preto, Ribeirão Preto, 2013

A hipóxia crônica intermitente (HCI) promove hipertensão arterial e aumento da atividade simpática em ratos jovens. Nestes animais, o aumento da atividade simpática ocorre durante uma fase específica da respiração e está correlacionada com o aumento da atividade expiratória. Estas evidências mostram que, após a HCI, os ratos jovens desenvolvem alterações no acoplamento simpático-respiratório, um mecanismo que pode contribuir, pelo menos em parte, para o desenvolvimento da hipertensão observada nestes animais. Em diversos modelos experimentais de hipertensão, os níveis de pressão arterial são menores nas fêmeas do que nos machos, portanto elas são resistentes ao desenvolvimento da hipertensão. Levando em conta essas informações, a hipótese do presente projeto foi a seguinte: fêmeas submetidas à HCI seriam resistentes ao desenvolvimento da hipertensão arterial. Para tanto, ratas jovens e adultas foram submetidas à HCI e seus parâmetros cardiovasculares e respiratórios foram avaliados na condição dos animais acordados e com livre movimentação. Além disso, as alterações na atividade simpática e respiratória também foram avaliadas na preparação coração tronco-cerebral isolados. Os resultados mostram que as fêmeas desenvolvem hipertensão semelhante aos machos submetidos ao mesmo protocolo, contudo as alterações no acoplamento entre a atividade simpática e respiratória são diferentes entre os sexos. Estes dados sugerem que embora os machos e fêmeas desenvolvam um nível 
similar de hipertensão após a HCI, os mecanismos envolvidos na geração da atividade simpática podem ser diferentes.

Palavras chaves: hipóxia crônica intermitente, hipertensão, fêmeas, acoplamento simpático-respiratório. 


\begin{abstract}
SOUZA, G.M.P.R. Cardiovascular and respiratory changes in female rats submitted to chronic intermittent hypoxia. $77 \mathrm{p}$. Thesis (Msc) - School of Medicine of Ribeirão Preto, Ribeirão Preto, 2013
\end{abstract}

Chronic intermittent hypoxia $(\mathrm{CIH})$ produces hypertension and sympathetic overactivity in juvenile male rats. The increase in sympathetic activity occurs during the expiratory phase of respiration, which is correlated with an augmented expiratory activity. This information indicates that after $\mathrm{CIH}$, juvenile rats develop changes in the respiratory sympathetic-coupling, which could explain, at least in part, the hypertension observed in these animals. Female rats are known to be more resistant to the development of hypertension in several experimental models of this pathology. Take in consideration these facts, we hypothesized that female rats exposed to $\mathrm{CIH}$ were resistant to the development of hypertension. To test this hypothesis, we studied the cardiovascular and respiratory changes in female rats after the $\mathrm{CIH}$ in awake freely moving condition. In another group of animals, we studied the sympathetic and respiratory activity in female rats after the $\mathrm{CIH}$, using for this, the working heartbrainstem preparation. The results show that juvenile female rats develop hypertension similarly to that observed in juvenile male rats submitted to the same protocol. However, juvenile female rats presented changes in the respiratory-sympathetic coupling different from that observed in juvenile male rats. Together, these results suggest that even if the level of hypertension after CIH is similar between males and females, the mechanisms underlying the generation of sympathetic overactivity are different. 


\section{LISTA DE FIGURAS}

Figura 1. Protocolo de hipóxia intermitente (esquerda) e de normóxia (direita). Observe que durante a hipóxia intermitente a $\mathrm{FiO}_{2}$ na câmara é reduzida a 6\%, caracterizando o episódio de hipóxia.

Figura 2. Esquema ilustrativo da preparação coração-tronco cerebral isolados.; tSNA: atividade do nervo simpático torácico; PN: atividade do nervo frênico; Modificado de Zoccal e cols. (2009).

Figura 3. Calibração para a quantificação da atividade simpática basal. Observe que no momento em que a bomba é desligada a pressão de perfusão cai e ocorre aumento da atividade simpática, o ponto máximo desta atividade foi considerado $100 \%$. Após a morte da preparação, o que resta é apenas o ruído da rede elétrica e nenhuma atividade simpática ( $0 \%)$.

Figura 4. Média de 10 ciclos respiratórios e da atividade simpática correspondente. O ciclo respiratório é inicialmente dividido em 3 fases. Note que a atividade simpática é modulada pela respiração, pois o aumento da atividade durante se correlaciona com o período da inspiração. Observe que a atividade simpática máxima durante a inspiração foi considerada $100 \%$.

Figura 5. Peso corporal médio dos ratos jovens submetidos à HCI. A. Peso corporal das fêmeas jovens submetidas à $\mathrm{HCI}(\mathrm{n}=38)$ e controle $(\mathrm{n}=36)$. B. Peso corporal dos machos jovens submetidos à $\mathrm{HCI}(\mathrm{n}=27)$ e controle $(\mathrm{n}=21) .(*) \mathrm{p}<0,05$. 40

Figura 6. Peso corporal médio das fêmeas adultas submetidas à HCI ( $n=27)$ e controle (n=26). $(*) \mathrm{p}<0,05$

Figura 7. Registro representativo dos parâmetros cardiovasculares e dos movimentos respiratórios de um animal representativo de cada grupo. PP, pressão arterial pulsátil; PAM, pressão arterial média; FC, frequência cardíaca. Observe que a PP, a PAM e a FC são maiores nos animais submetidos à HCI, tanto nas fêmeas jovens quanto nos machos jovens.

Figura 8. Evolução da PAS durante o desenvolvimento em ratos submetidos à HCI. A. Evolução da PAS em machos submetidos à $\mathrm{HCI}(\mathrm{n}=21)$ em relação ao seu controle $(\mathrm{n}=16)$. B. Evolução da PAS em fêmeas submetidas à HCI $(n=23)$ em relação ao seu controle $(n=25)$. Para comparações temporais, antes e após o protocolo, (\#) indica diferença estatística $(\mathrm{p}<0.05)$. Para comparações entre o tratamento, HCI e controle, $\left(^{*}\right)$ indica diferença estatística $(p<0.05)$...... 43

Figura 9. Pressão arterial média $(P A M)$ de fêmeas $(n=30)$ e machos $(n=27)$ jovens submetidos à HCI em relação ao seu controle fêmeas $(n=34)$ e machos $(n=21) .(*) p<0,05$. 44

Figura 10. PAS e PAD médias de ratos submetidos à HCI. A. PAS média de ratos submetidos à HCI, fêmeas $(n=30)$ e machos $(n=27)$ comparados com seu respectivo controle fêmeas $(n=34)$ e machos $(n=21)$. B. PAD de ratos submetidos à HCI em relação ao grupo controle. $\left({ }^{*}\right)$ p $<0,0545$

Figura 11. Frequência cardíaca média $(F C)$ de fêmeas $(n=30)$ e machos $(n=27)$ submetidos à HCI em relação ao seu respectivo controle, fêmeas $(n=30)$ e machos $(n=21) .(*) p<0,05$ 
Figura 12. Parâmetros respiratórios basais nas fêmeas $(n=24)$ e machos $(n=18)$ submetidos à HCI em relação ao seu respectivo controle fêmeas $(n=28)$ e machos $(n=15)$. A. Volume corrente médio $\left(V_{T}\right)$ B. Frequência respiratória média $\left(F_{R}\right)$ C. Ventilação-total média $\left(V_{E}\right) .\left(^{*}\right) p<0,05 . .47$

Figura 13. Parâmetros respiratórios basais nas fêmeas $(n=24)$ e machos $(n=18)$ jovens submetidos à HCI em relação ao seu respectivo controle fêmeas $(n=28)$ e machos $(n=15)$. A. Tempo de inspiração médio (s) B. Tempo médio de expiração (s) $\mathbf{C}$. Tempo médio de duração do ciclo respiratório. $(*) \mathrm{p}<0,05$

Figura 14. Parâmetros cardiovasculares em ratos adultos submetidos à HCI. A. Pressão arterial média (PAM) de fêmeas $(\mathrm{n}=27)$ e machos $(\mathrm{n}=41)$ adultos submetidos à $\mathrm{HCI}$ em relação ao seu controle fêmeas $(n=26)$ e machos $(n=38)$. B. Frequência cardíaca média $(F C)$ de ratos submetidos à HCI em relação ao seu respectivo controle. $(*) p<0,05$

Figura 15. Parâmetros respiratórios de fêmeas adultas submetidas à $\mathrm{HCI}(\mathrm{n}=27)$ em relação ao grupo controle $(n=26)$. A. Volume corrente médio $\left(V_{T}\right)$ B. Frequência respiratória média $\left(F_{R}\right) \mathbf{C}$. Ventilação-total média $\left(\mathrm{V}_{\mathrm{E}}\right)$.

Figura 16. Parâmetros respiratórios basais nas fêmeas adultas submetidas à $\mathrm{HCI}(\mathrm{n}=27) \mathrm{em}$ relação ao seu respectivo controle ( $\mathrm{n}=26) \mathbf{A}$. Tempo de inspiração médio (s) B. Tempo médio de expiração (s) C. Tempo médio de duração do ciclo respiratório. $(*) p<0,05$. 52

Figura 17. Parâmetros respiratórios na preparação coração-tronco cerebral isolados. A. Frequência respiratória nas fêmeas submetidas à $\mathrm{HCI}(\mathrm{n}=21)$ e controle $(\mathrm{n}=13)$. B. duração da expiração nas fêmeas submetidas à $\mathrm{HCI}$ e controle. C. Duração da inspiração nas fêmeas submetidas à HCI e controle. $(*) \mathrm{p}<0,05$

Figura 18. Padrão respiratório de ratas jovens submetidas à $\mathrm{HCI}(\mathrm{n}=21)$ e controle $(\mathrm{n}=13)$. A. Registros do nervo frênico de uma rata representativa do grupo controle e HCI. B. Média de 10 ciclos respiratórios (10 bursts do nervo frênico) de uma rata representativa do grupo controle e HCI.

Figura 19. Média da atividade simpática basal nas fêmeas submetidas à $\mathrm{HCI}(\mathrm{n}=6)$ e controle $(\mathrm{n}=4), \mathrm{p}=0.07$

Figura 20. Registro da atividade simpática e respiratória de uma fêmea representativa do grupo controle e do grupo HCI. Observe que o padrão respiratório está alterado na fêmea submetida à HCI, assim como a distribuição da atividade simpática durante essa fase do ciclo respiratório. 56

Figura 21. Acoplamento simpático-respiratório em fêmeas submetidas à HCI. A. Média da atividade simpática e do nervo frênico de 10 ciclos respiratórios de um animal representativo do grupo controle e HCI. B. Média dos valores de atividade simpática durante cada fase do ciclo respiratório. (*) $\mathrm{p}<0,05$

Figura 22. Progesterona plasmática média em ratas submetidas à HCI $(n=28)$ em relação ao seu respectivo controle $(n=23)$. $(*) p<0,05$... .58

Figura 23. Estradiol plasmático médio nas fêmeas submetidas à $\mathrm{HCI}(\mathrm{n}=22)$ em relação ao seu respectivo controle $(n=21)$. 
Figura 24. LH plasmático em ratas $(\mathrm{n}=29)$ submetidas à HCI em relação ao seu respectivo controle $(n=24)$.

Figura 25. Corticosterona plasmática média em ratas $(n=29)$ submetidas à HCI em relação ao seu respectivo controle $(n=25)$.

Figura 26. Concentração plasmática de estradiol em ratas adultas submetidas à $\mathrm{HCI}$ e controle de acordo com a fase do ciclo estral no dia do registro. (Estro HCI, $n=7$; Estro Controle, $n=8$; Diestro 1 HCI, $n=10$; Diestro 1 controle, $n=10$; Diestro 2 HCI, $n=9$; Diestro 2 controle, $n=8$ ). 61

Figura 27. Concentração plasmática de progesterona em ratas adultas submetidas à HCI e controle de acordo com a fase do ciclo estral no dia do registro. (Estro HCI, $n=7$; Estro Controle, $n=9$; Diestro 1 HCI, n=9; Diestro 1 controle, $n=9$; Diestro 2 HCI, n=9; Diestro 2 controle, $\mathrm{n}=6$ ). 


\section{SUMÁRIO}

1. INTRODUÇÃ

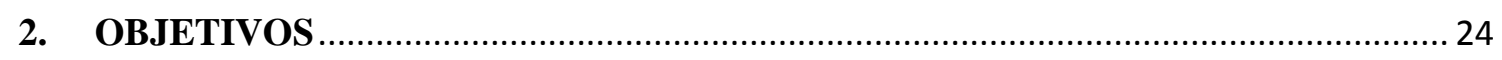

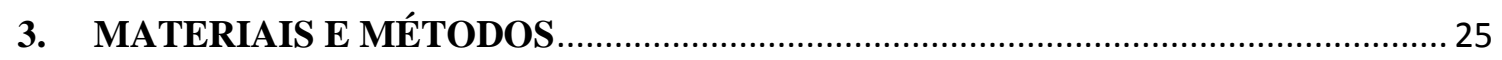

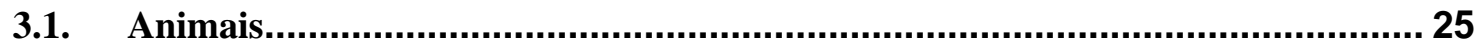

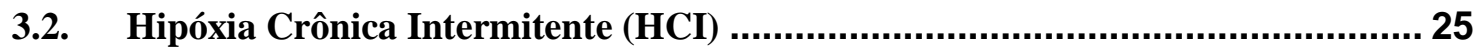

3.3. Procedimentos experimentais in vivo - Animal acordado …................................ 26

3.3.1. Avaliação dos parâmetros cardiovasculares basais em animais acordados.......... 26

3.3.2. Avaliação da frequência respiratória, volume corrente e ventilação em animais

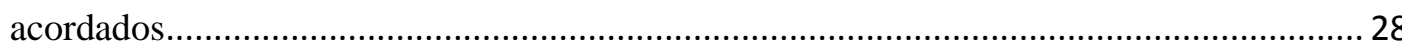

3.4. Procedimentos experimentais in situ - preparação coração-tronco cerebral

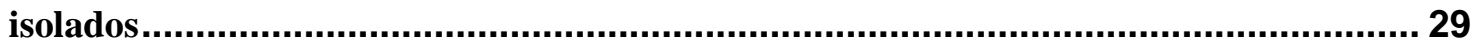

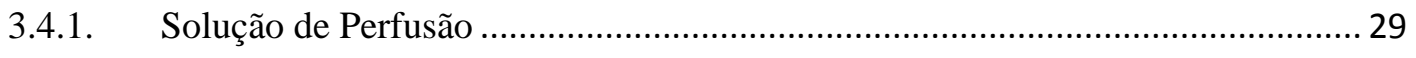

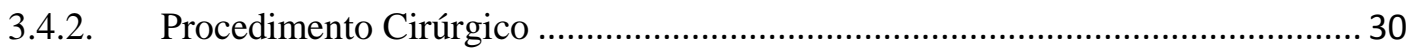

3.4.3. Registros da atividade do nervo simpático e frênico ............................................. 31

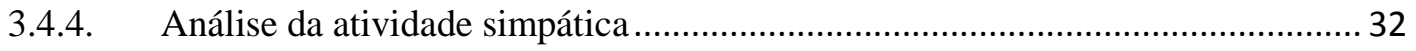

3.4.5. Análise do acoplamento-simpático respiratório ................................................... 34

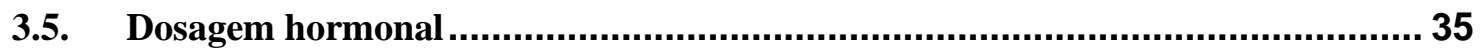

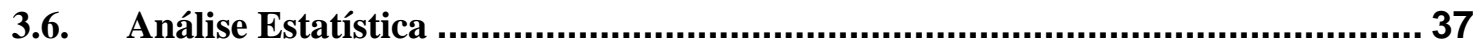

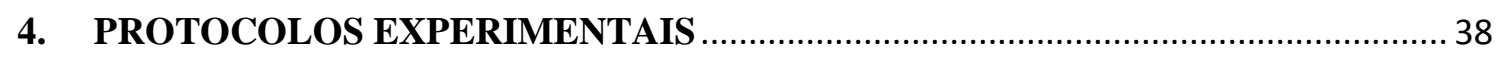

4.1. Protocolo 1 - Avaliação dos parâmetros cardiovasculares e respiratórios em

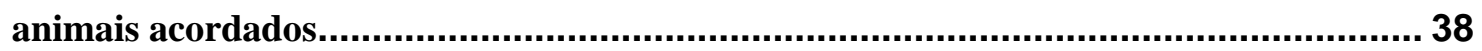

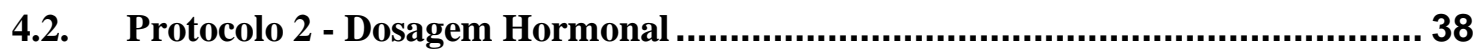

4.3. Protocolo 3 - Análise da atividade simpática e respiratória basal e do acoplamento simpático respiratório na preparação in situ ........................................ 38

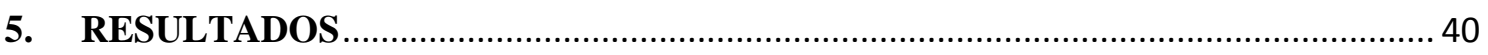

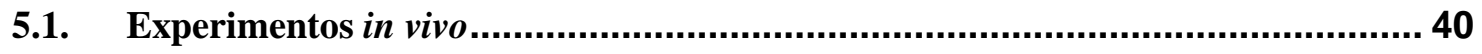

5.1.1. Peso corporal de animais submetidos à HCI …................................................. 40

5.1.2. Registros de pressão arterial pulsátil e dos movimentos respiratórios em animais

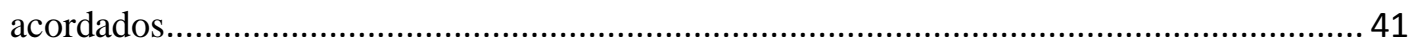

5.1.3. Evolução da PAS em animais jovens submetidos à HCI. ..................................... 43

5.1.4. Parâmetros cardiovasculares basais de ratos jovens expostos à HCI. .................. 44

5.1.5. Parâmetros respiratórios basais de ratos jovens expostos a HCI.......................... 46 
5.1.6. Parâmetros cardiovasculares de ratas adultas submetidas à HCI.

5.1.7. Parâmetros respiratórios basais de ratas adultas submetidas à HCI 50

5.2. Experimentos realizados na preparação in situ ............................................ 52

5.2.1. Padrão respiratório basal de fêmeas submetidas à HCI......................................... 52

5.2.2. Atividade simpática basal em fêmeas submetidas à HCI .................................... 54

5.2.3. Acoplamento simpático-respiratório em fêmeas submetidas à HCI .....................57

5.3. Concentração plasmática de hormônios sexuais em fêmeas submetidas à HCI ... 58

5.3.1. Concentração plasmática de progesterona em fêmeas jovens submetidas à HCI. 58

5.3.2. Concentração plasmática de estradiol em fêmeas jovens submetidas à HCI. .....58

5.3.3. Concentração plasmática de LH nas fêmeas jovens submetidas à HCI ............... 59

5.3.4. Concentração plasmática de corticosterona em fêmeas jovens submetidas à HCI 60

5.3.5. Concentração plasmática de estradiol em fêmeas adultas submetidas à HCI .....60 60

5.3.6. Concentração plasmática de progesterona em fêmeas adultas submetidas à HCI 61

6. DISCUSSÃO

6.1. Alterações cardiovasculares em ratas submetidas à HCI

6.2. Alterações respiratórias em ratas submetidas à HCI no modelo do animal acordado.

6.3. Alterações no padrão respiratório basal de ratas submetidas à HCI na preparação in situ

6.4. Alterações no acoplamento-simpático respiratório de ratas submetidas à HCI ... 68

6.5. Concentração de hormônios sexuais no plasma de ratas submetidas à HCI........ 68

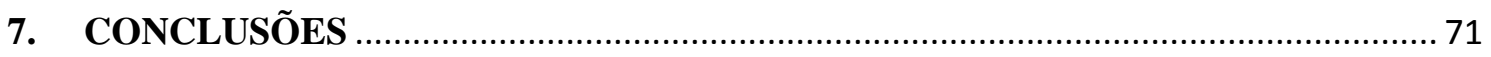

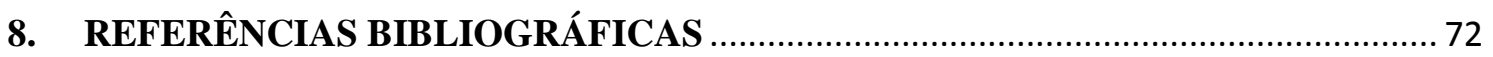




\section{INTRODUÇÃO}

Os sistemas cardiovascular e respiratório são imprescindíveis para a homeostasia do meio interno de mamíferos. O sistema nervoso central (SNC) é fundamental para a regulação cardiovascular e respiratória, otimizando e ajustando os seus ritmos de acordo com as possíveis alterações internas ou externas que coloquem em risco a homeostasia do organismo. Os principais elementos dos circuitos neurais responsáveis por esta regulação encontram-se no tronco cerebral, especificamente, nas porções bulbares e pontinas (Feldman \& Ellenberger, 1988).

Para executar funções tão precisas, os mamíferos possuem sistemas sensoriais constituídos de células especializadas, localizados na bifurcação das carótidas e no arco aórtico, denominados barorreceptores arteriais e quimiorreceptores periféricos. Os barorreceptores são mecanorreceptores que se despolarizam frente às variações de pressão arterial, propagando potenciais de ação para regiões bulbares no SNC. Alterações na resistência dos vasos, na contratilidade e frequência cardíaca fazem parte das respostas autonômicas do SNC frente à estimulação dos barorreceptores, a fim de manter a pressão arterial em níveis adequados (Krieger, 1964; Cowley e cols., 1974; Thomas, 2011).

Os quimiorreceptores periféricos são células que detectam as variações de pressão parcial do oxigênio no sangue arterial $\left(\mathrm{PaO}_{2}\right)$. O reflexo ativado pelos quimiorreceptores, ou quimiorreflexo, produz ajustes cardiovasculares e respiratórios que otimizam a captação e distribuição de oxigênio para todas as células e tecidos do organismo (Machado, 2001; Kara e cols., 2003). Durante episódios de hipóxia, por exemplo, os quimiorreceptores periféricos detectam a queda na $\mathrm{PaO}_{2}$ e ao se despolarizarem propagam potenciais de ação para os núcleos bulbares através da estimulação das fibras aferentes dos nervos cranianos. Quando estas regiões específicas do SNC são ativadas por estes estímulos excitatórios promovem alterações no sistema cardiovascular e 
respiratório, como o aumento de pressão arterial, bradicardia e aumento da frequência respiratória (Franchini \& Krieger, 1993; Haibara e cols., 1999; Barros e cols., 2002). Contudo, a exposição a períodos repetitivos de hipóxia, como a hipóxia crônica intermitente (HCI), caracterizada pela ativação frequente $\mathrm{e}$ intermitente dos quimiorreceptores periféricos, resulta em alterações mantidas na atividade simpática e no padrão respiratório (Zoccal e cols., 2008).

Estudos de Zoccal e cols. (2008) mostraram o aumento na pressão arterial e na atividade simpática em ratos jovens submetidos à HCI. Sabe-se que a elevação da pressão arterial nesse modelo experimental é dependente da integridade dos quimiorreceptores arteriais (Fletcher e cols., 1992). Estudos do nosso laboratório mostraram que as respostas simpáticas e respiratórias frente à ativação do quimiorreflexo estão aumentadas em animais que foram submetidos à HCI: a resposta simpática está aumentada, a bradicardia é mais pronunciada e o aumento da frequência de disparo do frênico é mais prolongado frente à ativação do quimiorreflexo periférico (Braga e cols., 2006).

Um aspecto importante relacionado ao sistema respiratório é a sua capacidade de influenciar a atividade simpática (Malpas, 1998, 2010; Zoccal e cols., 2009b). Essa relação, denominada acoplamento simpático-respiratório, associa a ventilação com variações no débito cardíaco e distribuição do fluxo sanguíneo para os pulmões, otimizando a troca de gases (Simms e cols., 2010; Moraes e cols., 2012). Acredita-se que o mecanismo gerador do aumento da atividade simpática em animais submetidos à HCI está relacionado às alterações no acoplamento entre neurônios respiratórios e simpáticos na região ventral do bulbo (Zoccal e cols., 2009b; Moraes e cols., 2012). Portanto, a HCI é um modelo experimental que pode causar alterações em redes neurais responsáveis pelo controle autonômico e respiratório, induzindo plasticidade neuronal nas diferentes redes e sinapses envolvidas (Abdala e cols., 2009; Kline, 2010). 
Evidências experimentais indicam que o desenvolvimento da hipertensão arterial no modelo de HCI está relacionado ao aumento da atividade simpática resultante das alterações no acoplamento simpático-respiratório (Zoccal \& Machado, 2011; Zoccal e cols., 2008). Quadros de hipertensão arterial associados ao aumento da atividade simpática também estão presentes em pacientes com apneia obstrutiva do sono [(AOS) (Somers e cols., 1995)]. A AOS é uma patologia que se caracteriza pelo colapso das vias aéreas superiores durante o sono, levando a episódios de hipóxia repetitivos e transitórios como no modelo de HCI (Kapur, 2010).

A hipertensão arterial é um dos maiores problemas de saúde pública e objeto de estudo em diversos laboratórios do mundo. Sabe-se que essa patologia atinge com maior frequência as pessoas do sexo masculino do que aquelas do feminino (Reckelhoff, 2001). Em mulheres após a menopausa, quando há uma queda na produção de hormônios sexuais (estrógeno e progesterona), o risco de se desenvolver hipertensão aumenta, indicando que fatores hormonais podem ter um papel importante na prevenção desta patologia (Hayward e cols., 2000; Reckelhoff, 2001).

O dimorfismo sexual também é observado em modelos experimentais de hipertensão. Em animais espontaneamente hipertensos (SHR), por exemplo, as fêmeas apresentam menor nível de pressão arterial (cerca de $30 \mathrm{mmHg}$ menor) do que os machos desta linhagem (Reckelhoff, 2001). Além disso, a androgenização de fêmeas SHR ovariectomizadas promove aumento na pressão arterial (Reckelhoff, 2001). Do mesmo modo, existe diferença entre gêneros no desenvolvimento da hipertensão no modelo de infusão de ANG II, no qual as fêmeas apresentam menor nível pressão arterial quando comparadas com machos ou fêmeas ovariectomizadas (Xue e cols., 2005). Em ratos da linhagem Dahl (Dahl S) sal-sensível, os quais se caracterizam por desenvolver hipertensão em resposta a dietas ricas em sódio, as fêmeas também apresentam menor nível de pressão arterial em relação aos machos (Rowland \& Fregly, 1992). Além disso, a 
castração de machos neonatos desta linhagem promove atenuação no aumento dos níveis de pressão arterial na vida adulta (Rowland \& Fregly, 1992). No modelo de hipertensão induzido por desoxicorticosterona (DOCA), as fêmeas também apresentam níveis menores níveis de pressão arterial em relação aos machos (Ouchi e cols., 1987). Este conjunto de evidências sugere que os hormônios sexuais influenciam o desenvolvimento da hipertensão arterial.

Além da influência dos hormônios, genes presentes nos cromossomos sexuais também podem explicar as diferenças entre sexos no desenvolvimento da hipertensão e no controle cardiovascular (Caeiro e cols., 2011). Em ratos SHR, por exemplo, o desenvolvimento da hipertensão parece estar ligado ao cromossomo sexual Y desses animais (Ely \& Turner, 1990). A atividade simpática envolvendo o sistema noradrenérgico é maior em machos que possuem o cromossomo Y provenientes de SHR, do que em machos com cromossomos provenientes de ratos normotensos (Caplea e cols., 2002).

Os neurônios bulbares da região rostral, ventral e lateral do bulbo (rostral ventrolateral medulla, RVLM), responsáveis pela geração da atividade simpática, também são diferentes entre os sexos. As diferenças podem ser encontradas na maior expressão de receptores de angiotensina do tipo $\mathrm{AT}_{1}$ e na menor expressão de NADPH oxidase em neurônios pré-simpáticos do RLVM de fêmeas, o que pode ter impacto na geração da atividade simpática e na manutenção dos níveis de pressão arterial (Dampney, 2008; Wang e cols., 2008).

Sugere-se, deste modo, que o sexo é um fator determinante no desenvolvimento da hipertensão em diferentes modelos experimentais desta patologia. Portanto, a questão que se coloca no contexto do presente projeto é a seguinte: poderiam essas diferenças entre sexos, relacionadas ao desenvolvimento da hipertensão, estarem presentes também no modelo de HCI? 
Além do dimorfismo sexual relacionado ao controle das funções cardiovasculares em nível genético, hormonal e neural, alguns trabalhos também apontam diferenças no controle da respiração entre machos e fêmeas. Por exemplo, um estudo realizado em ratos mostrou que a resposta ventilatória à hipóxia ou hipercapnia é dependente da idade e do sexo, principalmente em animais entre o $10^{\circ}$ e $15^{\circ}$ dia após o nascimento, sendo que estas diferenças não são mais observadas após esta idade (Holley e cols., 2012). Outro estudo realizado por Mortola \& Saiki em 1996 mostrou que a resposta ventilatória à hipóxia é maior em fêmeas jovens ou adultas do que em machos da mesma idade. Além disso, foi mostrado que a castração das fêmeas não tem influencia sobre esta resposta, sugerindo que ela pode ser independente dos hormônios sexuais (Mortola \& Saiki, 1996).

Do mesmo modo que ocorre com o controle da pressão arterial, existe uma série de evidências de que os hormônios sexuais podem influenciar as redes neurais envolvidas no controle da respiração em ratos e em humanos (Behan e cols., 2003). Em um estudo realizado em gatos, a castração de machos e fêmeas reduziu a resposta respiratória à hipóxia, mostrando papel de hormônios sexuais masculinos e femininos neste reflexo (Tatsumi e cols., 1991). Experimentos realizados com ratos anestesiados mostram que o aumento na atividade do nervo frênico em situações de hipóxia pode ser influenciado pela fase do ciclo estral e pela idade (Zabka e cols., 2001). Em ratos acordados, a resposta ventilatória à hipóxia é maior em fêmeas senis quando comparadas com machos da mesma idade (Wenninger e cols., 2009).

As evidências sobre a influência do sexo no controle respiratório não se limitam apenas aos estudos com animais, mas também podem ser encontradas em estudos clínicos com pacientes. Distúrbios respiratórios, como a AOS, são mais prevalentes em homens do que em mulheres, e a prevalência entre as mulheres aumenta após a menopausa (Bixler e cols., 2001). 
O sistema hormonal também é influenciado pelo sexo durante o desenvolvimento. Sabe-se, que os machos são expostos a concentrações plasmáticas elevadas de testosterona durante a vida intra-uterina e nas primeiras horas de nascimento, diferente do que ocorre nas fêmeas nesta fase (Zapatero-Caballero e cols., 2003). Além disso, as fêmeas produzem estrógeno e não testosterona na fase pré-púbere e as concentrações plasmáticas de progesterona, corticosterona e LH são diferentes entre machos e fêmeas nesta fase (Viau e cols., 2005).

Levando em conta essas informações, a hipótese do presente projeto é a seguinte: as fêmeas devem ser resistentes ao desenvolvimento da hipertensão no modelo de HCI. Para testar essa hipótese, estudamos o desenvolvimento de hipertensão, o padrão respiratório e o acoplamento simpático-respiratório em fêmeas submetidas à HCI. Para tanto, em uma primeira etapa foi feita a caracterização das alterações cardiovasculares e respiratórias de ratas jovens submetidas à HCI durante 10 dias utilizando o modelo de animal acordado. Na segunda etapa utilizamos a preparação coração-tronco cerebral isolados, para a caracterização de possíveis alterações no acoplamento simpáticorespiratório das fêmeas jovens submetidas à HCI. 


\section{OBJETIVOS}

a) Verificar os efeitos da HCI sobre os parâmetros cardiovasculares e respiratórios de ratas jovens acordadas.

b) Verificar se existem alterações no acoplamento simpático-respiratório em ratas jovens submetidas à HCI na preparação coração-tronco cerebral isolados. 


\section{MATERIAIS E MÉTODOS}

\subsection{Animais}

Foram utilizadas 108 fêmeas e 48 machos Wistar (19-21 dias) e 53 ratas Wistar adultas (55-60 dias) fornecidas pelo Serviço de Biotério Central do Campus da USP de Ribeirão Preto e mantidas em caixas coletivas (no máximo oito animais por caixa) no Biotério de Manutenção e Experimentação do Departamento de Fisiologia da FMRPUSP. Os animais foram mantidos em ambiente com temperatura média de $22^{\circ} \mathrm{C}$, ciclo de claro-escuro artificial de 12 horas e alimentados com ração granulada e água ad libitum. Os experimentos foram realizados com a aprovação dos protocolos experimentais do projeto pelo CETEA-FMRP-USP (protocolo nº 188/2011).

\subsection{Hipóxia Crônica Intermitente (HCI)}

Os animais foram submetidos à HCI pelo seguinte protocolo: os animais foram expostos a 1 episódio de hipóxia a cada 9 minutos, diariamente, por 8 horas, entre 9:30 e 17:30, durante 10 dias consecutivos para ratos jovens e 35 dias consecutivos para ratas adultas (Zoccal e cols., 2007a; Zoccal e cols., 2007b). Em cada episódio, os animais foram expostos durante 5 minutos a uma fração de $\mathrm{O}_{2}$ do ar inspirado $\left(\mathrm{FiO}_{2}\right)$ de $20,8 \%$ (normóxia), seguido de 4 minutos de injeção de $\mathrm{N}_{2}$ a $100 \%$ que promoveu a redução da $\mathrm{FiO}_{2}$ de para $6 \%$, permanecendo neste nível por aproximadamente 40 segundos (Figura 1). Após este período, o $\mathrm{O}_{2}(100 \%)$ foi injetado na câmara até o retorno da $\mathrm{FiO}_{2}$ a 20,8 \%. Os animais do grupo controle foram mantidos em câmaras semelhantes àquelas utilizadas para a indução dos episódios de hipóxia, no entanto, sem a indução de hipóxia (normóxia). 


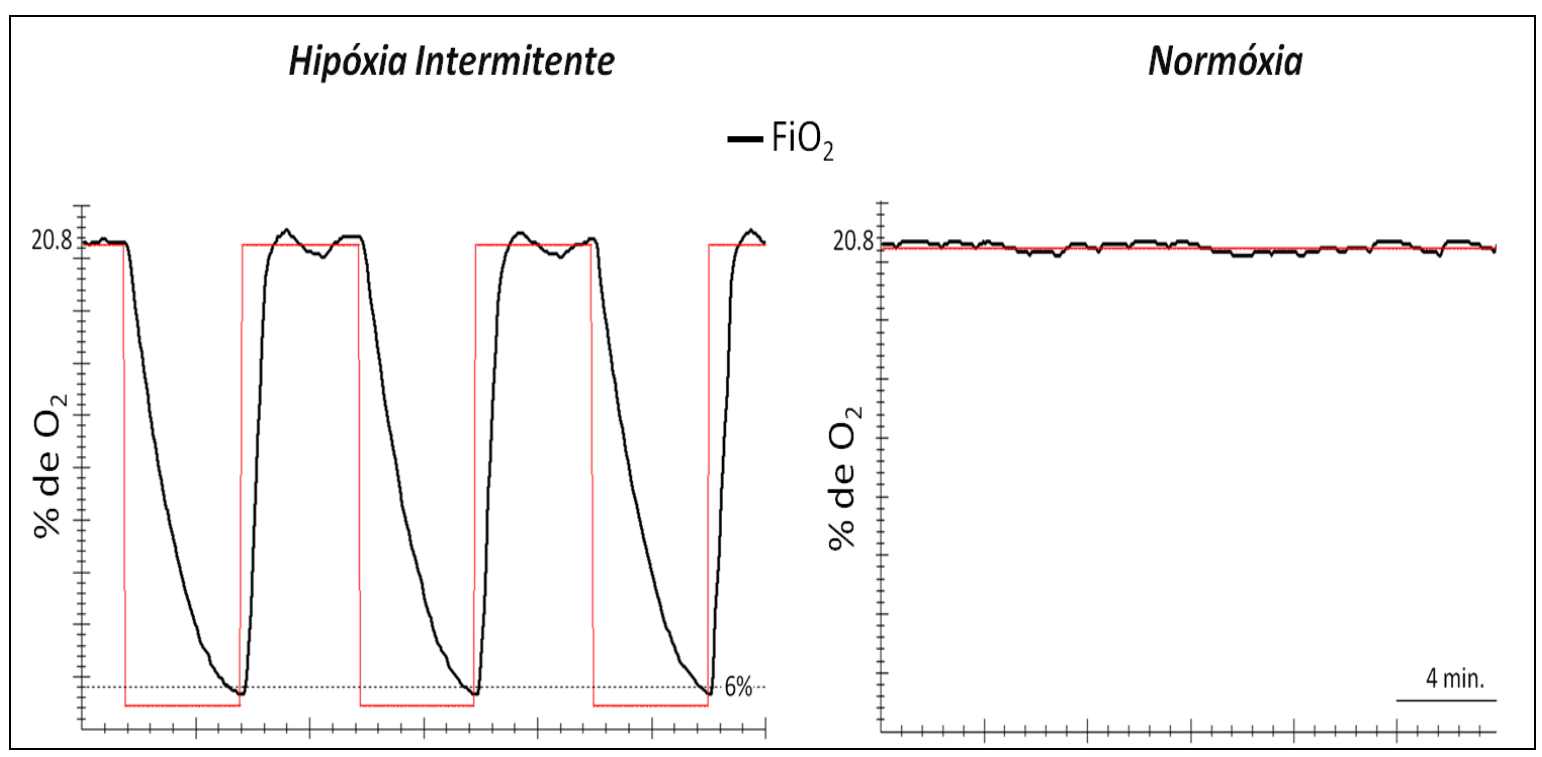

Figura 1. Protocolo de hipóxia intermitente (esquerda) e de normóxia (direita). Observe que durante a hipóxia intermitente a $\mathrm{FiO}_{2}$ na câmara é reduzida a 6\%, caracterizando o episódio de hipóxia.

3.3. Procedimentos experimentais in vivo - Animal acordado

3.3.1. Avaliação dos parâmetros cardiovasculares basais em animais acordados

Para a análise da evolução da pressão arterial sistólica (PAS) durante o tempo e o efeito promovido pela HCI nesta variável, a PAS de ratas jovens foi avaliada antes e após a exposição à HCI, pelo método de pletismografia de cauda, como descrito por Zoccal e cols. (2009). Para tanto, antes da medida da PAS, os animais foram mantidos em uma câmara aquecida a $31-32^{\circ} \mathrm{C}$ por 10 minutos, período necessário para promover a vasodilatação da cauda do animal. Após este período, os animais foram mantidos dentro de um cilindro de acrílico e a cauda do animal foi posicionada em um sensor/oclusor (model 31, IITC Life Science, Woodland Hills, EUA). Em seguida, o sensor/oclusor foi inflado de modo a interromper a pulsação arterial da cauda do animal. Quando o 
sensor/oclusor era desinflado, o restabelecimento das pulsações era detectado, medindo desta forma a PAS de maneira indireta.

Após os 10 dias de protocolo, os animais do grupo controle e HCI, foram cateterizados para a medida direta da pressão arterial. Para isso, os animais foram anestesiados com o tribromo-etanol (250 mg/kg, i.p.; Aldrich, Milwuakee, EUA) e um cateter (PE-10 conectado a PE-50, Clay Adams, Parsippany, EUA) foi implantado na aorta abdominal, através da artéria femoral direita. Após a implantação do cateter, ele foi exteriorizado subcutaneamente no dorso do animal. Como medida profilática foi administrado intramuscularmente $1 \mathrm{mg} / \mathrm{kg}$ de peso do analgésico e antitérmico fluxina meglumina (Banamine, Schering-Plough) ao término da cirurgia. No dia seguinte a cirurgia, quando as ratos estavam recuperados da anestesia e adaptados a sala de registro, o cateter implantado no animal foi conectado a um transdutor de pressão (MLT0380, ADInstruments, Bella Vista, Austrália), o qual estava conectado a um amplificador (Bridge Amp, ML221, ADInstruments, Bella Vista, Austrália), e deste modo foi obtido o registro da pressão arterial pulsátil (PAP). Os sinais da PAP foram adquiridos por um sistema de aquisição (PowerLab 4/25, ML845, ADInstruments, Bella Vista, Austrália) e registrados por meio do software LabChart versão 5.0 (Chart Pro, ADInstruments, Bella Vista, Austrália) em uma frequência de aquisição de $1 \mathrm{kHz}$. A partir dos sinais da PAP foram obtidos os valores da pressão arterial diastólica (PAD), sistólica (PAS) e média (PAM), e da frequência cardíaca (FC). Os parâmetros cardiovasculares foram registrados em animais acordados com livre movimentação por períodos de 40 à 50 minutos e os dados obtidos durante os últimos 30 minutos foram considerados para análise. 
3.3.2. Avaliação da frequência respiratória, volume corrente e ventilação em animais acordados

Os movimentos respiratórios foram registrados pelo método de pletismografia de corpo inteiro, como descrito em estudos anteriores do nosso laboratório (Granjeiro e cols., 2009). Para estes experimentos, o animal foi mantido dentro de uma câmara de acrílico (volume de 6L), a qual foi vedada e as oscilações de pressão causadas pela respiração do animal, devido a diferença de temperatura entre o ar inspirado e o ar expirado, foram detectadas por meio de um transdutor de pressão (ML141 Spirometer, PowerLab, ADInstruments, Bella Vista, Austrália), conectado a um sistema de aquisição (PowerLab 4/25, ML845, ADInstruments, Bella Vista, Australia). Os sinais foram registrados em um computador através do software LabChart versão 5.0, a uma frequência de aquisição de $1 \mathrm{kHz}$ (Chart Pro, ADInstruments, Bella Vista, Australia). A frequência respiratória $\left(F_{R}\right)$ de cada animal foi quantificada a partir do intervalo de tempo entre os sucessivos ciclos respiratórios e foi expressa em ciclos por minuto (cpm).

Durante os experimentos, a temperatura no interior da câmara pletismográfica e da sala de experimentos foram constantemente monitoradas. Ao final de cada registro dos parâmetros respiratórios, foi realizada a calibração do registro por meio da injeção de 1 $\mathrm{mL}$ de ar dentro da câmara $\left(\mathrm{V}_{\mathrm{K}}\right)$. Para calcular o volume corrente $\left(\mathrm{V}_{\mathrm{T}}\right)$, os valores da amplitude dos ciclos respiratórios em $\mathrm{mV}$ foram quantificados e aplicados à equação abaixo, de acordo com a descrição de Drorbaugh e cols (1955):

$$
\mathrm{V}_{\mathrm{T}}=\mathrm{V}_{\mathrm{K}} \mathrm{x} \mathrm{PT} / \mathrm{P}_{\mathrm{K}} \mathrm{x}\left(\mathrm{T}_{\mathrm{C}}(\mathrm{PB}-\mathrm{PA})\right) /\left(\mathrm{T}_{\mathrm{C}}(\mathrm{PB}-\mathrm{PA})-(\mathrm{TA}(\mathrm{PB}-\mathrm{PC})\right.
$$

Na qual:

$\mathrm{V}_{\mathrm{K}}$ : volume de ar injetado na câmara do animal para calibração; 
PT : alteração de pressão associada a cada ciclo respiratório;

$\mathrm{P}_{\mathrm{K}}$ : alteração de pressão associada ao volume de ar injetado para a calibração;

$\mathrm{T}_{\mathrm{C}}:$ temperatura corporal;

TA: temperatura do ar dentro da câmara;

PB: pressão barométrica;

PC: pressão de vapor d'água à temperatura corporal;

PA: pressão de vapor d'água à temperatura da câmara.

Os valores de $\mathrm{V}_{\mathrm{T}}$ calculados foram corrigidos pelo peso de cada animal, deste modo, expressos em mL/kg. A ventilação $\left(V_{E}\right)$ foi calculada pelo produto de $F_{R}$ e $V_{T}$, o qual foi expressa em $\mathrm{mL} / \mathrm{kg} / \mathrm{min}$. A duração do ciclo respiratório $\left(\mathrm{T}_{\text {tot }}\right)$ e a duração da inspiração $\left(\mathrm{T}_{\mathrm{i}}\right)$ e da expiração $\left(\mathrm{T}_{\mathrm{e}}\right)$ também foram quantificados e expressos em milissegundos (ms).

3.4. Procedimentos experimentais in situ - preparação coração-tronco cerebral isolados

\subsubsection{Solução de Perfusão}

A solução utilizada na perfusão da preparação (líquido cérebro-espinhal artificial modificado, aCSF), foi diluída em água deionizada e composta por (em mM): 125 de $\mathrm{NaCl} ; 24$ de $\mathrm{NaHCO}_{3} ; 5$ de $\mathrm{KCl} ; 2,5$ de $\mathrm{CaCl}_{2} ; 1,25$ de $\mathrm{MgSO}_{4} ; 1,25$ de $\mathrm{KH}_{2} \mathrm{PO}_{4}$ e 20 de D-glicose. Foram adicionados também a essa solução um agente oncótico (Polietilenoglicol, Sigma, MO, EUA) e a solução foi borbulhada com uma mistura carbogênica $\left(95 \%\right.$ de $\mathrm{O}_{2}$ e $5 \%$ de $\mathrm{CO}_{2}$ ). No início do experimento foi adicionado aproximadamente $80 \mu \mathrm{L}$ de arginina-vasopressina $(4 \mu \mathrm{M})$ à solução de perfusão para 
promover vasoconstrição no animal e o aumento da resistência periférica, com o objetivo de aumentar a pressão de perfusão. Para bloquear os movimentos respiratórios do animal utilizamos um bloqueador da transmissão neuromuscular (Brometo de vecurônio 0,4 mg/ml, Cristália, Brasil), adicionado à solução de perfusão quando o animal iniciava os movimentos respiratórios.

\subsubsection{Procedimento Cirúrgico}

O animal, após ser profundamente anestesiado com halotano, foi hemi-seccionado e as vísceras foram retiradas. A cabeça e o tórax foram imersos em aCSF gelado e em seguida, o animal foi descerebrado ao nível pré-colicular com o auxílio de uma seringa de sucção. A parte lateral superior esquerda do tórax (costelas e musculatura associada) foi removida ao nível torácico médio para melhor exposição dos nervos e para permitir o acesso dos eletrodos de registro aos nervos frênico e simpático.

Após a cirurgia, o animal foi transferido para a cuba de registro e a aorta descendente foi canulada e perfundida retrogradamente com aCSF modificado, com o auxílio de uma bomba peristáltica (Watson-Marlow, 520U, IP3; Falmouth, Inglaterra). A pressão de perfusão foi mantida constante entre 50 e 60 mmHg e a perfusão foi realizada com um fluxo de aproximadamente $25 \mathrm{~mL} / \mathrm{min}$. O perfusato foi constantemente aerado com a mistura carbogênica e aquecido por meio de um trocador de calor, de modo que a temperatura final da solução de perfusão era de aproximadamente $30^{\circ} \mathrm{C}$. O perfusato foi filtrado com um pré-filtro de polipropileno com poros com $25 \mathrm{~mm}$ de diâmetro, para evitar que pequenas partículas chegassem até o animal (Millipore, PP25, Billerica, EUA). Finalmente, o perfusato passou através de duas armadilhas para bolhas, a fim de evitar a passagem de bolhas para o interior do animal e para amortecer as pulsações geradas pela bomba peristáltica, garantindo um fluxo constante (Figura 2). 
O cateter conectado à artéria do animal é um cateter de duplo lúmen, sendo um utilizado para a perfusão e outro para o registro da pressão de perfusão (PP) do animal. Essa cânula foi conectada a um transdutor de pressão (PT 300, Grass Instruments, West Warwick, EUA) e o sinal foi amplificado (AVS, São Carlos, Brasil) conectado a um computador, e os dados foram registrados por meio do software Spike 2 (Cambrigde Electronic Design, Cambridge, UK).

\subsubsection{Registros da atividade do nervo simpático e frênico}

Após o isolamento e secção do nervo frênico, foi feita a sucção deste nervo com o eletrodo de sucção e sua atividade foi registrada. O eletrodo estava conectado a um préamplificador (Filtro: 5kHz-300 Hz, Insight Equipamentos, Ribeirão Preto, SP, Brasil) e a um computador, o qual utilizou o programa Spike 2 (Cambrigde Electronic Design, Cambridge, UK) para a aquisição e digitalização dos registros, à uma frequência de aquisição de $5 \mathrm{kHz}$. O nervo eferente simpático torácico também foi isolado, seccionado e sua atividade registrada, seguindo procedimentos semelhantes para o registro da atividade do nervo frênico (Filtro: $5 \mathrm{kHz}-5 \mathrm{~Hz}$, frequência de aquisição do sinal: $5 \mathrm{kHz}$ ). Por meio destes registros, foi possível obter um índice da atividade simpática e respiratória. A atividade simpática foi retificada e integrada a uma constante de tempo de 50 ms. Com o registro desses dois nervos estabelecemos a relação entre as atividades simpática e respiratória, bem como a distribuição da atividade simpática nas diferentes fases do ciclo respiratório. 


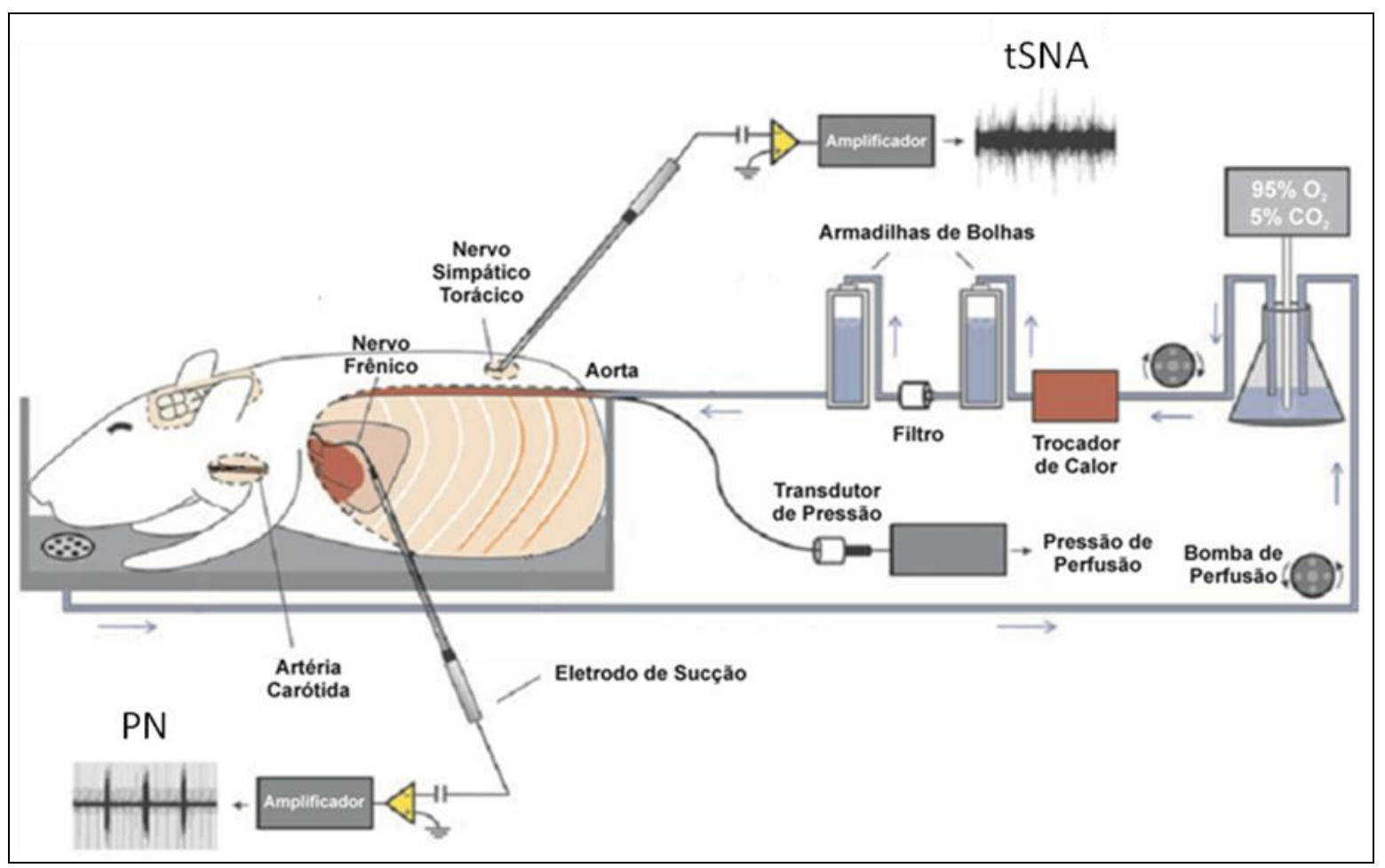

Figura 2. Esquema ilustrativo da preparação coração-tronco cerebral isolados.; tSNA: atividade do nervo simpático torácico; PN: atividade do nervo frênico; Modificado de Zoccal e cols. (2009).

\subsubsection{Análise da atividade simpática}

O registro da atividade do nervo simpático permite a quantificação da atividade simpática média. A análise da atividade simpática foi feita a partir da média da sua atividade integrada a uma constante de integração de $50 \mathrm{~ms}$. Contudo, o registro de nervos por meio desta abordagem é multifibras, portanto não é possível definir o número de fibras registradas em cada protocolo. Deste modo, a atividade do nervo em $\mu \mathrm{V}$, pode ser muito variável de acordo com o número de fibras registradas. Para tornar possível a comparação entre animais experimentais, a atividade simpática foi corrigida com base na atividade simpática máxima e no ruído elétrico, obtidos ao final do protocolo, quando a bomba de perfusão foi desligada. Durante o desligamento da bomba ocorre um aumento abrupto da atividade simpática e o valor máximo desta atividade ( $\left.\mathrm{V}_{\mathrm{MÁx}}\right)$ neste período foi 
considerado como $100 \%$ de atividade. Após 15 minutos do desligamento da bomba de perfusão, não foi registrado nenhuma atividade simpática ou respiratória da preparação $(0 \%)$, sendo registrado então, apenas o ruído da rede elétrica $\left(\mathrm{V}_{\mathrm{MíN}}\right)$. Um exemplo de como foi feita a calibração pode ser observado na figura 3 .

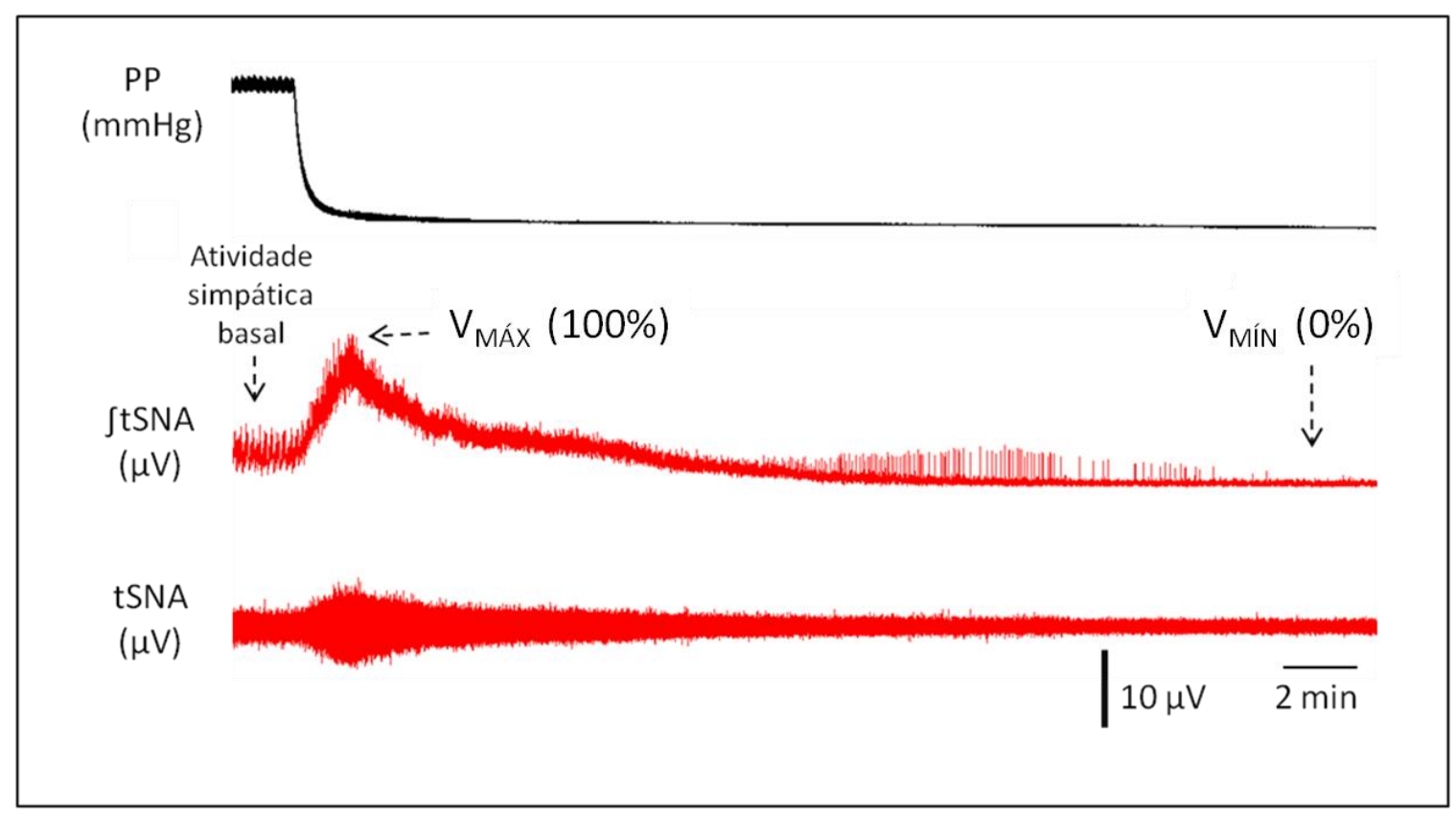

Figura 3. Calibração para a quantificação da atividade simpática basal. Observe que no momento em que a bomba é desligada a pressão de perfusão cai e ocorre aumento da atividade simpática, o ponto máximo desta atividade foi considerado $100 \%$. Cerca de quinze minutos após o desligamento da bomba, o que resta

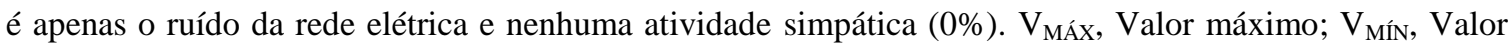
mínimo.

Para a quantificação da atividade simpática basal foi feita a média da atividade simpática basal durante 60 segundos. $\mathrm{O}$ valor obtido em $\mu \mathrm{V}$ foi calculado de acordo com a seguinte fórmula:

$$
\text { tSNA }(\%)=\left(\text { valor }-\mathrm{V}_{\text {MíN }}\right) /\left(\mathrm{V}_{\text {MÁx }}-\mathrm{V}_{\text {MíN }}\right) \text { x 100, }
$$


onde, valor $=$ valor médio da atividade simpática integrada, $\mathrm{V}_{\mathrm{MÁx}}=$ atividade máxima obtida após a isquemia, $\mathrm{V}_{\mathrm{MÍN}}=$ ruído elétrico, $\mathrm{tSNA}=$ atividade do nervo simpático torácico $(\%)$

\subsubsection{Análise do acoplamento-simpático respiratório}

Para a análise do acoplamento-simpático respiratório, primeiramente foi feita a média de 10 ciclos respiratórios (10 surtos do nervo frênico) e da atividade simpática correspondente a este período. Em seguida, o ciclo respiratório foi divido em 3 fases, sendo que a fase correspondente a duração do surto do nervo frênico foi considerada a fase inspiratória (INSP), e a porção silente foi considerada a fase expiratória. A primeira metade da fase expiratória foi denominada de expiração inicial (E1) e a segunda metade da expiração foi considerada a expiração final (E2). Feito isso, calculamos a média da atividade simpática em cada uma das 3 fases da respiração. Como mencionado anteriormente, o registro de nervos na preparação é multifibras e para isso necessita de uma calibração em cada registro para a quantificação adequada. Neste caso, consideramos a atividade máxima do nervo simpático durante a inspiração como $100 \%$ e o ruído elétrico obtido ao final dos experimentos como $0 \%$. Com isso, obtivemos para cada preparação uma escala de 0 a $100 \%$, e quantificamos a atividade simpática entre esses valores utilizando a mesma fórmula para a quantificação da atividade simpática basal. Um exemplo da quantificação pode ser visualizado na figura 4. 


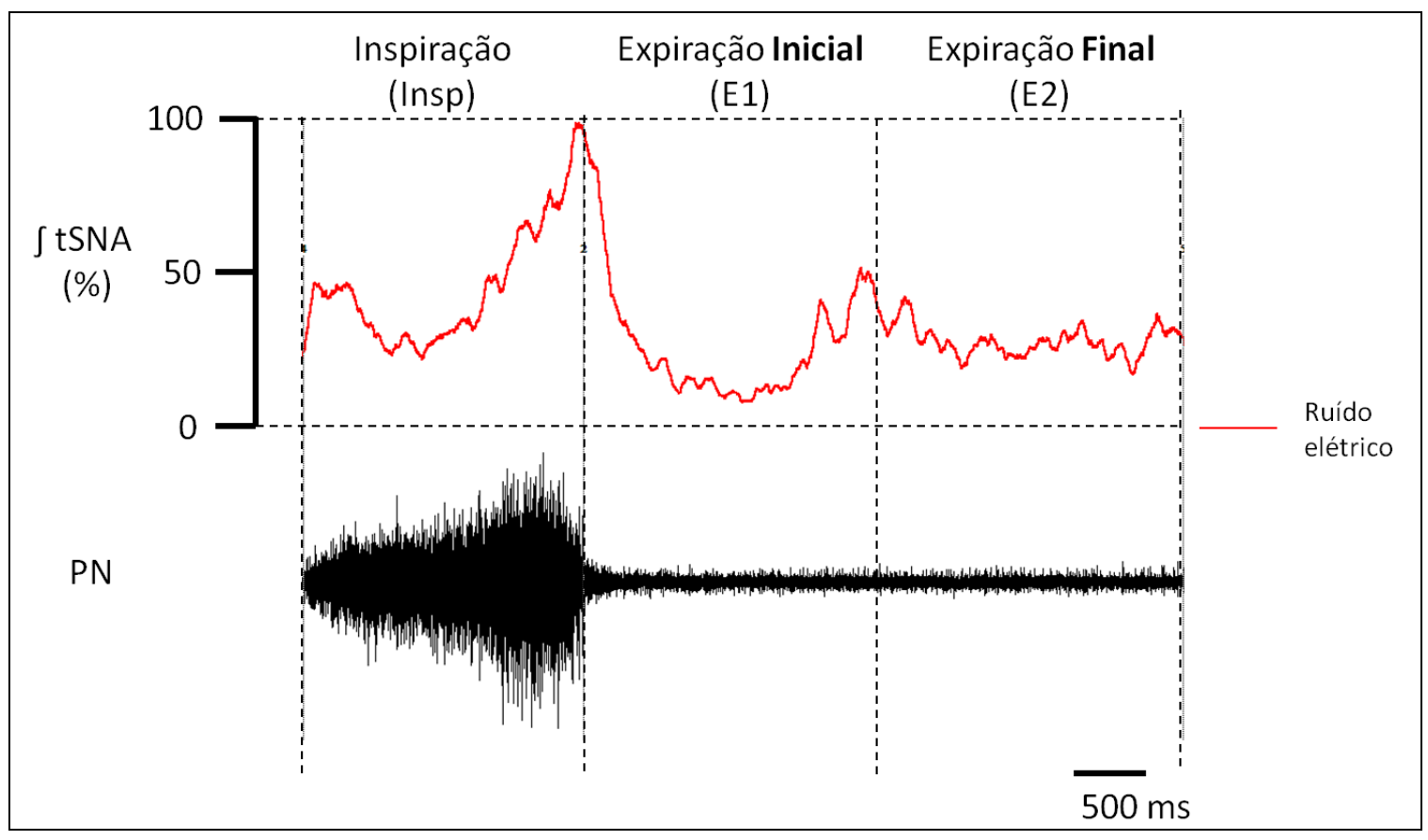

Figura 4. Média de 10 ciclos respiratórios e da atividade simpática correspondente. O ciclo respiratório é inicialmente dividido em 3 fases. Note que a atividade simpática é modulada pela respiração, pois o aumento da atividade durante se correlaciona com o período da inspiração. Observe que a atividade simpática máxima durante a inspiração foi considerada $100 \%$.

\subsection{Dosagem hormonal}

A dosagem dos hormônios sexuais foi importante para identificar possíveis alterações no sistema hormonal em animais submetidos à HCI. Esta análise nos permitiu identificar às concentrações hormonais nas ratas controle e especialmente naquelas submetidas à HCI. Para tanto, foram feitas as dosagens de estrógeno, progesterona e do hormônio luteinizante ( $\mathrm{LH})$. Também foi realizada a dosagem de corticosterona, um hormônio indicador de estresse. A corticosterona também pode influenciar os mecanismos simpáticos centrais e periféricos e foi visto que em ratos machos adultos submetidos à HCI suas concentrações plasmáticas estão aumentadas (Zoccal e cols., 2007a). 
Para as dosagens hormonais, os mesmos animais utilizados nos registros dos parâmetros cardiovasculares e respiratórios descritos no item 3.3. foram decapitados ao final dos registros e as amostras de sangue foram coletadas dos grupos controle e HCI. A coleta de sangue foi feita com o mínimo de estresse possível ao animal de acordo com os métodos utilizados pelos laboratórios de neuroendocrinologia da Faculdade de Medicina de Ribeirão Preto, descritos por Poletini e cols. (2003), Zoccal e cols. (2007a) e Elias e cols. (2004). As amostras sanguíneas coletadas foram centrifugadas à $4^{\circ} \mathrm{C}, 3500 \mathrm{rpm}$, por 20 minutos, o plasma separado e estocado a $-20^{\circ} \mathrm{C}$ até os procedimentos para dosagens hormonais de estrógeno, progesterona, LH e corticosterona pelo método de radioimunoensaio (RIE).

A dosagem das concentrações plasmáticas de cortiscosterona foi realizada após extração com etanol, utilizando padrão e anticorpo específico adquiridos da Sigma Co. (St. Louis, Missouri, USA) e corticosterona triciada adquirida (NEN Radiochemicals, Boston-MA,USA). A dose mínima detectável foi $0,1 \mathrm{ng} / \mathrm{mL}$. Os erros intra- e inter-ensaio foram de $4,5 \%$ e $11 \%$, respectivamente.

A progesterona foi determinada por meio de conjunto de reagentes para RIE (MP Biomedicals, LLC Diagnostics Division, Solon-OH, USA) e a dose mínima detectável foi 0,03 ng/mL como descrito por Traslavina \& Franci, (2011). Os erros intra- e inter-ensaio foram de $3,5 \%$ e $6 \%$, respectivamente. O estrógeno plasmático também foi determinado usando um conjunto de reagentes (Biochem ImuunoSystemns MAIA, Itália) e a dose mínima detectável foi $2,5 \mathrm{pg} / \mathrm{mL}$. Os erros intra- e inter-ensaio foram de $2,5 \%$ e $8 \%$, respectivamente. As concentrações plasmáticas de LH foram determinadas por RIE de duplo anticorpo, com anticorpos específicos e padrões adquiridos junto ao National Hormones and Peptides Program (Harbor-UCLA,USA). O anticorpo inespecífico para a precipitação da reação do RIE é produzido em ovelha pelo laboratório do Prof. Dr. Celso Rodrigues Franci, do Departamento de Fisiologia da FMRP-USP. Neste mesmo 
laboratório foi feita a iodinação e purificação do hormônio utilizado no ensaio. A dose mínima detectável foi $0,05 \mathrm{ng} / \mathrm{mL}$. Os erros intra- e inter-ensaio foram de $4 \%$ e $10 \%$, respectivamente.

\subsection{Análise Estatística}

Os resultados obtidos foram expressos como média \pm erro padrão da média. Para comparações diretas entre os diferentes parâmetros avaliados no grupo controle e no grupo HCI foi utilizado o teste $t$ de Student não pareado e para comparações entre diferentes grupos controle e HCI foi utilizado ANOVA two-way, seguido pelo pós-teste de Bonferroni quando necessário. Os gráficos e a análise estatística foram feitos por meio do programa GraphPad Prism (versão 4, GraphPad, La Jolla, USA) e o nível de significância estabelecido foi de 5\% ( $\mathrm{p}<0.05)$. 


\section{PROTOCOLOS EXPERIMENTAIS}

4.1. Protocolo 1 - Avaliação dos parâmetros cardiovasculares e respiratórios em animais acordados

Este protocolo teve como objetivo analisar os parâmetros cardiorrespiratórios basais em animais acordados submetidos por 10 ou 35 dias à HCI. Os animais cateterizados foram colocados em uma câmara pletismográfica e conectados a um transdutor de pressão. A pressão arterial, frequência cardíaca e os movimentos respiratórios basais foram registrados durante 40 a 50 minutos. Esses parâmetros foram analisados e posteriormente, submetidos à análise estatística.

\subsection{Protocolo 2 - Dosagem Hormonal}

Os mesmos animais utilizados no protocolo 1 foram decapitados e o sangue foi coletado do grupo controle e HCI e o plasma foi separado das amostras por centrifugação. $\mathrm{O}$ plasma foi armazenado em condições ideais a $20^{\circ} \mathrm{C}$. As concentrações dos hormônios estrógeno, progesterona, LH e corticosterona foram determinados por radioimunoensaio a partir do plasma coletado.

4.3. Protocolo 3 - Análise da atividade simpática e respiratória basal e do acoplamento simpático respiratório na preparação in situ

Este protocolo teve como objetivo analisar a atividade simpática e respiratória basais em ratas jovens submetidas à HCI por 10 dias, por tanto utilizamos a preparação coração-tronco cerebral isolados. Também foi analisado o acoplamento 
simpático-respiratório, e para tanto foi feita a quantificação da atividade simpática nas diferentes fases da respiração. 


\section{RESULTADOS}

\subsection{Experimentos in vivo}

5.1.1. Peso corporal de animais submetidos à HCI

Os ratos jovens submetidos à HCI (Fêmeas: $56 \pm 1$ vs $89 \pm 1 \mathrm{~g}$; Machos: $53 \pm 1$

vs $97 \pm 1 \mathrm{~g})$ ganharam menos peso quando comparado com seus respectivos controles

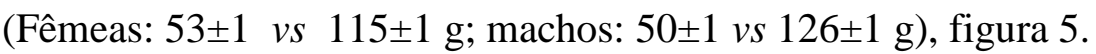

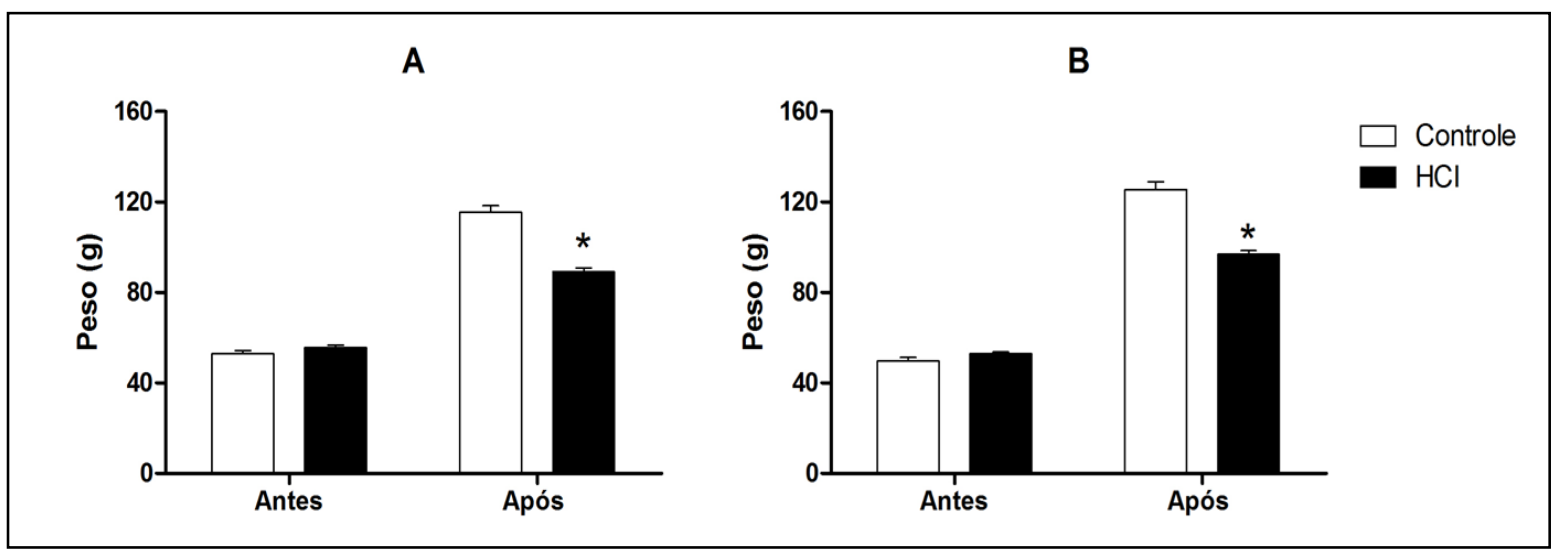

Figura 5. Peso corporal médio dos ratos jovens (19-21 dias) antes do protocolo (HCI ou controle) e após 10 dias. A. Peso corporal das fêmeas jovens submetidas à HCI $(n=38)$ e controle $(n=36)$. B. Peso corporal dos machos jovens submetidos à $\mathrm{HCI}(\mathrm{n}=27)$ e controle $(\mathrm{n}=21) .\left({ }^{*}\right) \mathrm{p}<0,05$

As fêmeas adultas submetidas à HCI (243 \pm 3 vs $273 \pm 3$ g) também ganharam menos peso em relação ao seu controle $(242 \pm 2$ vs $348 \pm 5 \mathrm{~g})$, antes a após o protocolo respectivamente. Os dados estão sumarizados na figura 6. 


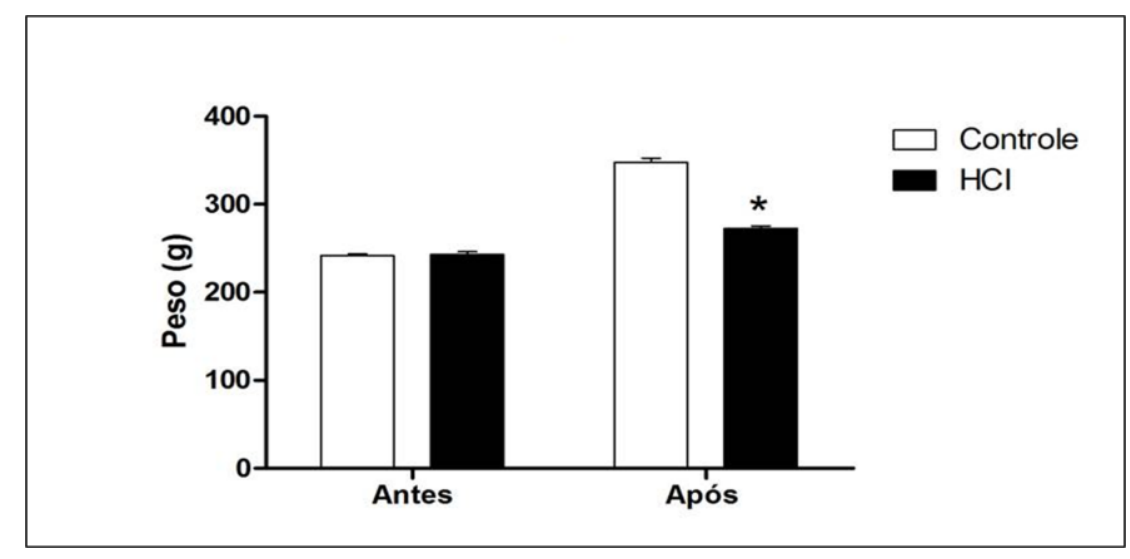

Figura 6. Peso corporal médio das fêmeas adultas antes do protocolo (HCI, n=27 e controle, n=26) e após 35 dias. $(*) \mathrm{p}<0,05$

5.1.2. Registros de pressão arterial pulsátil e dos movimentos respiratórios em animais acordados

A figura 7 mostra exemplos de registros da pressão arterial pulsátil (PP) e dos movimentos respiratórios em ratos acordados submetidos à HCI ou normóxia de ambos os sexos. A pressão arterial média e a frequência cardíaca foram derivadas do sinal de PP. 


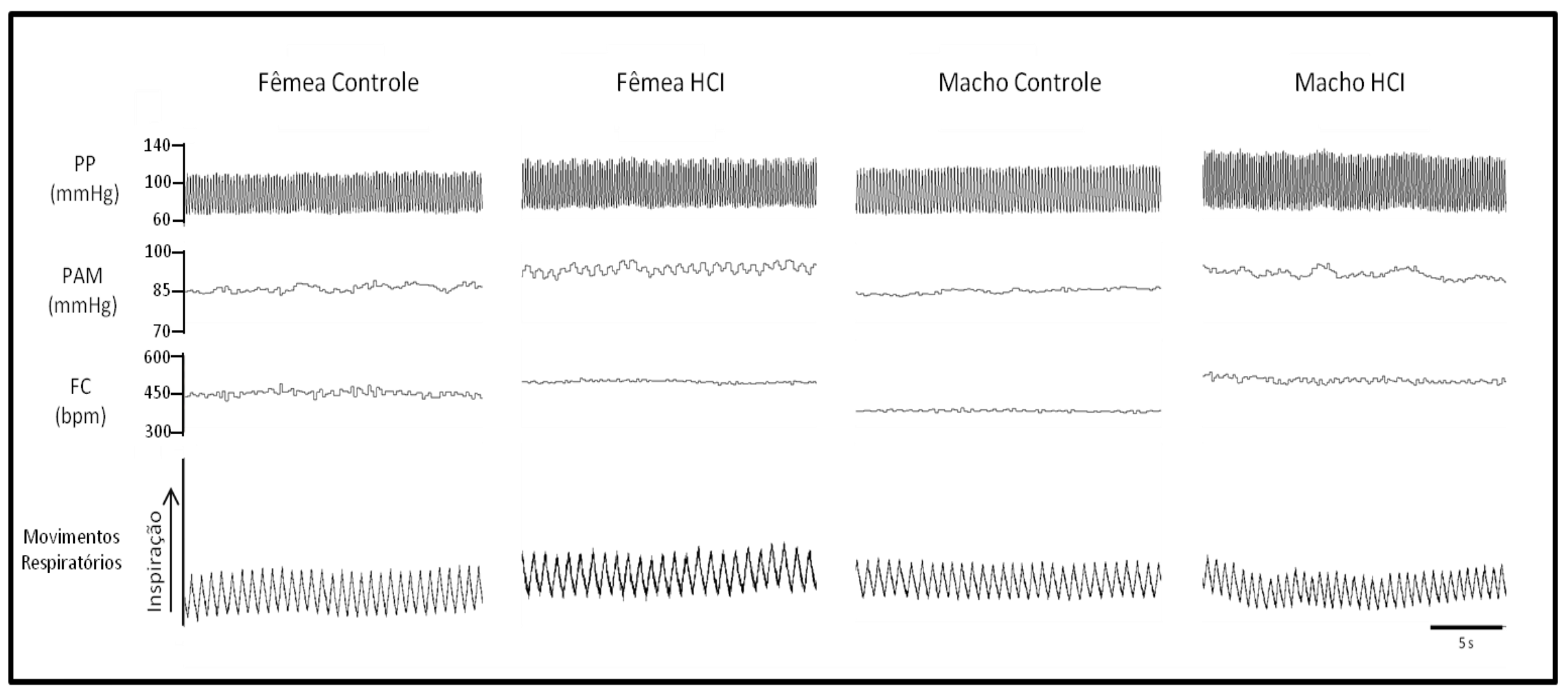

Figura 7. Registro representativo dos parâmetros cardiovasculares e dos movimentos respiratórios de um animal representativo de cada grupo. PP, pressão arterial pulsátil; PAM, pressão arterial média; FC, frequência cardíaca. Observe que a PP, a PAM e a FC são maiores nos animais submetidos à HCI, tanto nas fêmeas jovens quanto nos machos jovens. 


\subsubsection{Evolução da PAS em animais jovens submetidos à HCI.}

As fêmeas e os machos jovens do grupo controle acompanhados do $20^{\circ}$ ao $31^{\circ}$ dia de vida apresentaram aumento nos níveis médios de PAS durante dez dias (Fêmeas: 93 \pm 3 vs 115 2 mmHg; Machos: $92 \pm 2$ vs 116 \pm 2 mmHg). A PAS das fêmeas submetidas à HCI também aumentou durante 10 dias, mas não foi significativamente maior do que o seu respectivo grupo controle $(94 \pm 2$ vs $120 \pm 2 \mathrm{mmHg})$. A PAS dos machos submetidos à HCI aumentou significativamente durante 10 dias e foi maior em relação ao seu respectivo controle $(93 \pm 2$ vs $123 \pm 2 \mathrm{mmHg})$. Os dados estão sumarizados na figura 8 .

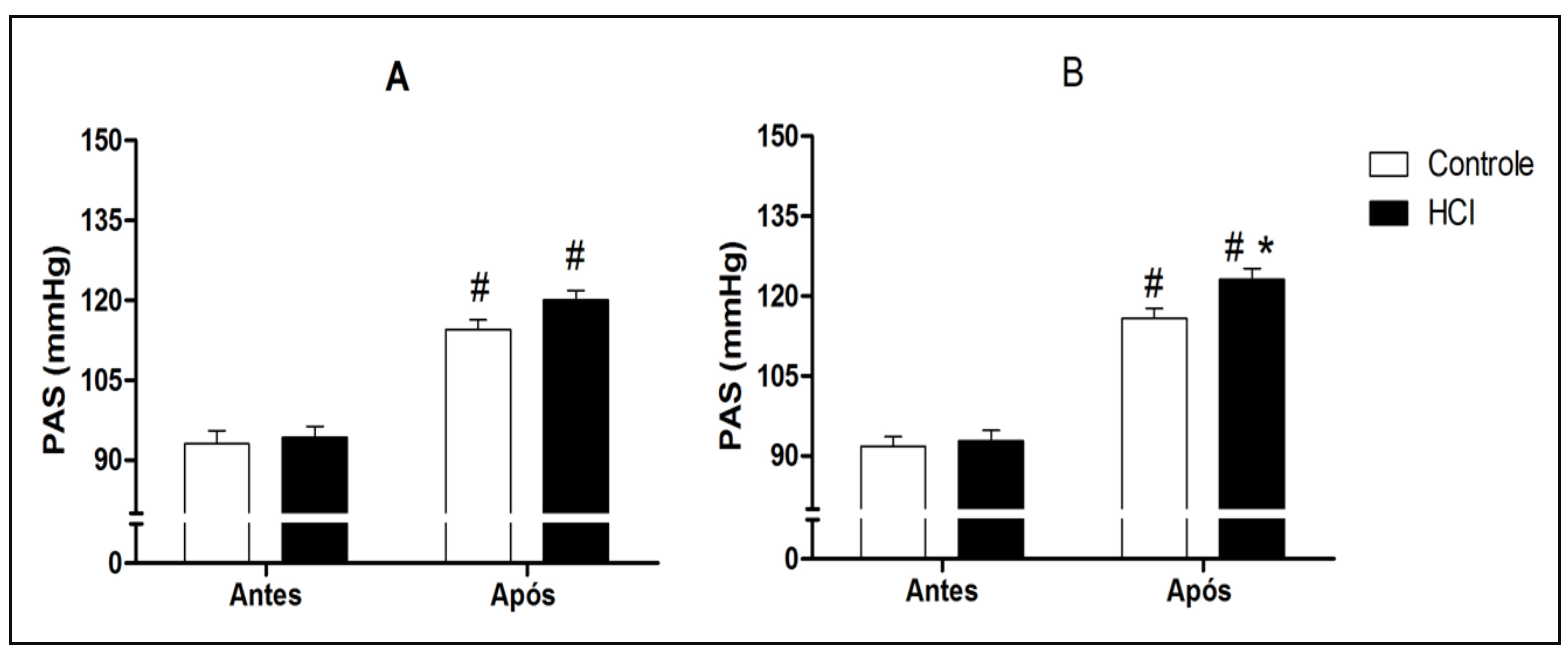

Figura 8. Evolução da PAS durante o desenvolvimento em ratos submetidos à HCI. A. Evolução da PAS em machos submetidos à HCI $(n=21)$ em relação ao seu controle $(n=16)$. B. Evolução da PAS em fêmeas submetidas à HCI $(n=23)$ em relação ao seu controle $(n=25)$. Para comparações temporais, antes e após o protocolo, $(\#)$ indica diferença estatística $(\mathrm{p}<0.05)$. Para comparações entre o tratamento, HCI e controle, $\left(^{*}\right)$ indica diferença estatística $(\mathrm{p}<0.05)$. 


\subsubsection{Parâmetros cardiovasculares basais de ratos jovens expostos à HCI.}

As fêmeas jovens submetidas à HCI apresentaram aumento nos níveis de PAM quando comparadas com o grupo controle $(94 \pm 1$ vs $86 \pm 1 \mathrm{mmHg})$ assim como os machos submetidos à HCI em relação aos seus respectivos controles $(94 \pm 1$ vs $87 \pm 1$ $\mathrm{mmHg}$ ), figura 9.

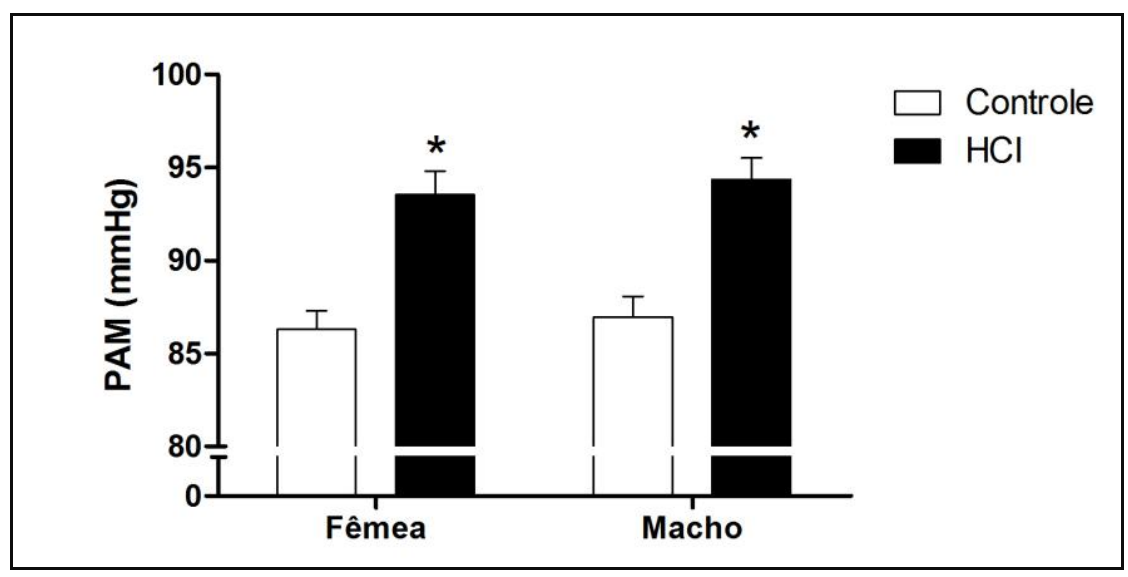

Figura 9. Pressão arterial média $(P A M)$ de fêmeas $(n=30)$ e machos $(n=27)$ jovens submetidos à HCI em relação ao seu controle fêmeas $(n=34)$ e machos $(n=21) .(*) p<0,05$

Do mesmo modo, os animais submetidos à HCI apresentaram PAS elevada quando comparada com a dos seus respectivos controles, fêmeas (118 \pm 2 vs $112 \pm 2$ $\mathrm{mmHg})$ e machos $(123 \pm 2$ vs $115 \pm 2 \mathrm{mmHg})$, avaliadas por meio da medida direta. O sexo teve influencia nos valores de PAS, uma vez que a PAS foi significativamente maior nos machos do que nas fêmeas, contudo o aumento promovido pela HCI foi da mesma magnitude. A PAD também estava aumentada nos animais do grupo experimental comparado com o seu respectivo grupo controle, fêmeas $(74 \pm 1$ vs $68 \pm 1 \mathrm{mmHg})$ e machos (74 \pm 1 vs $66 \pm 1 \mathrm{mmHg}$ ). Os dados estão representados na figura 10 . 


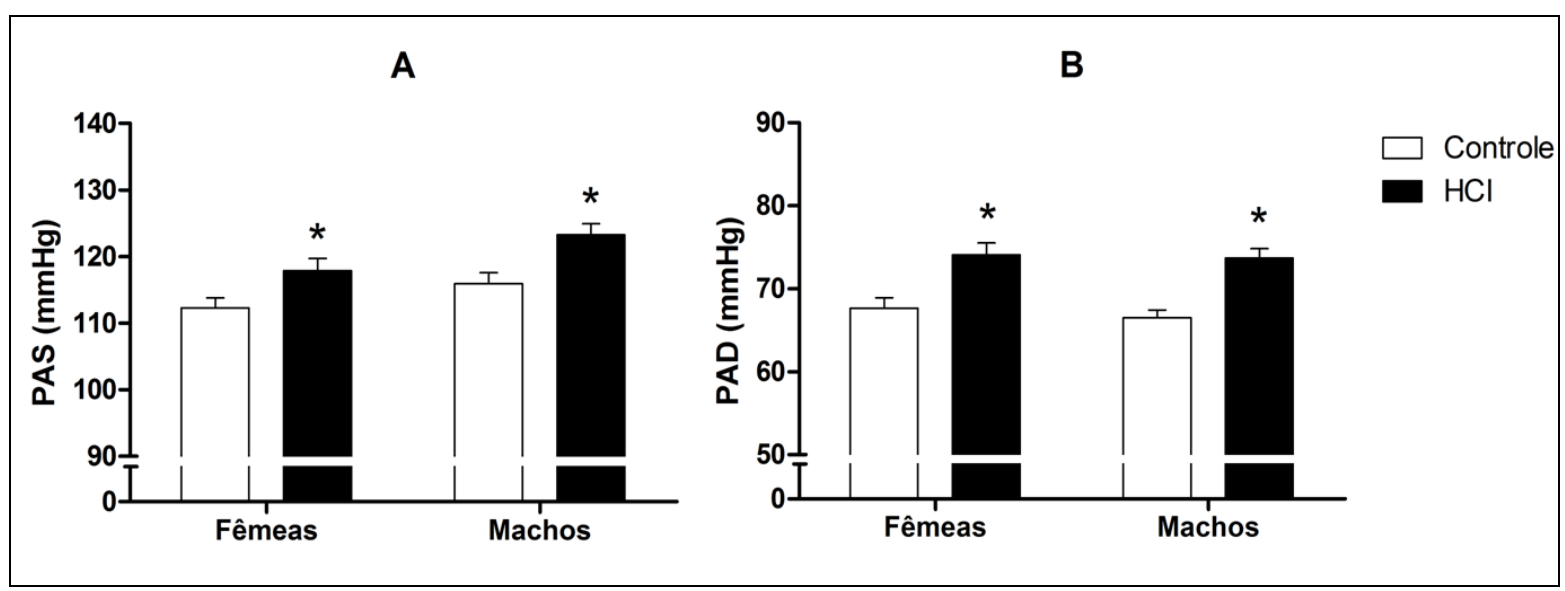

Figura 10. PAS e PAD médias de ratos submetidos à HCI. A. PAS média de ratos submetidos à HCI, fêmeas $(n=30)$ e machos $(n=27)$ comparados com seu respectivo controle fêmeas $(n=34)$ e machos $(n=21)$. B. PAD de ratos submetidos à HCI em relação ao grupo controle. (*) p<0,05

Também foi observada diferença significativa na FC dos animais submetidos

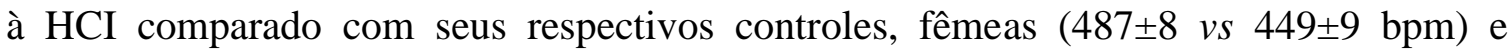

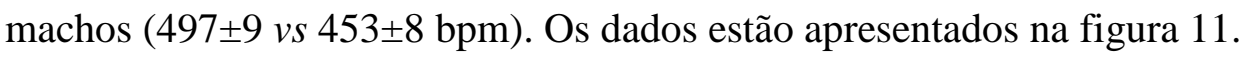

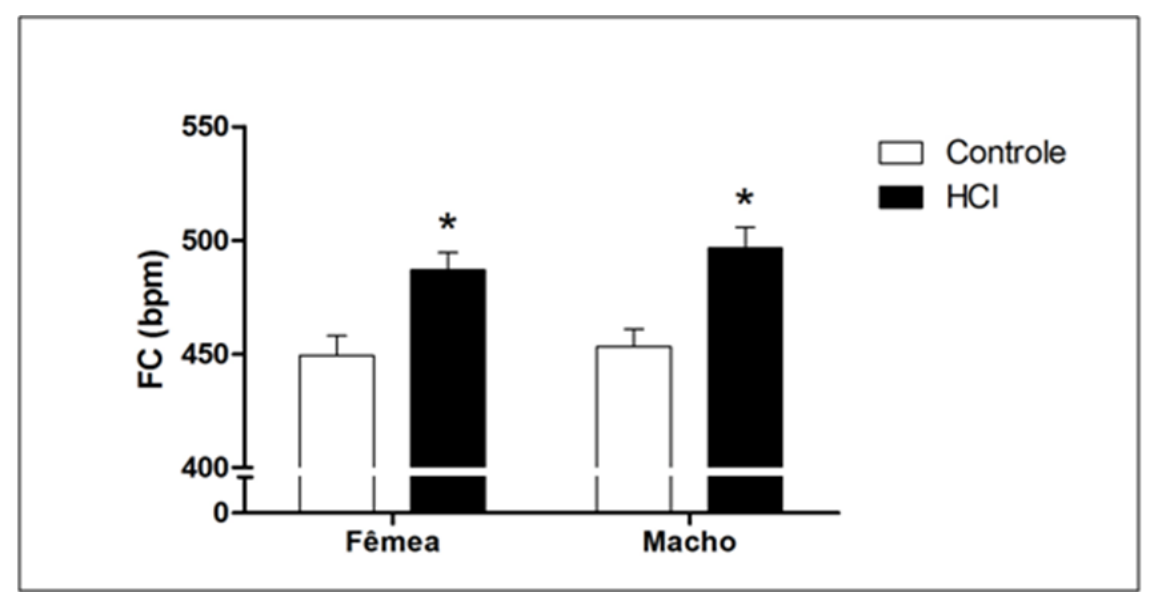

Figura 11. Frequência cardíaca média $(F C)$ de fêmeas $(n=30)$ e machos $(n=27)$ submetidos à HCI em relação ao seu respectivo controle, fêmeas $(n=30)$ e machos $(n=21) .(*) p<0,05$ 
5.1.5. Parâmetros respiratórios basais de ratos jovens expostos a HCI.

Alguns parâmetros respiratórios se apresentaram alterados nos animais submetidos à HCI em experimentos em animais acordados. As ratas jovens submetidas à HCI apresentaram aumento no volume corrente quando comparadas com o grupo controle $(14,7 \pm 0,5$ vs $11,8 \pm 0,52 \mathrm{ml} / \mathrm{kg})$ assim como os ratos machos $(14,1 \pm 0,6$ vs $11,2 \pm 0,4 \mathrm{ml} / \mathrm{kg}$ ). Não houve alterações significativas na frequência respiratória dos animais submetidos à HCI comparados com seus controles, fêmeas $(115 \pm 3$ vs $109 \pm 4$

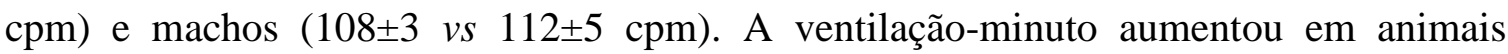
submetidos à HCI em relação aos seus respectivos controles, fêmeas $(1687,5 \pm 70$ vs $1293,7 \pm 71 \mathrm{ml} / \mathrm{kg} / \mathrm{min})$ e machos $(1519,8 \pm 74$ vs $1249,6 \pm 67 \mathrm{ml} / \mathrm{kg} / \mathrm{min})$. Os dados estão apresentados na figura 12 . 


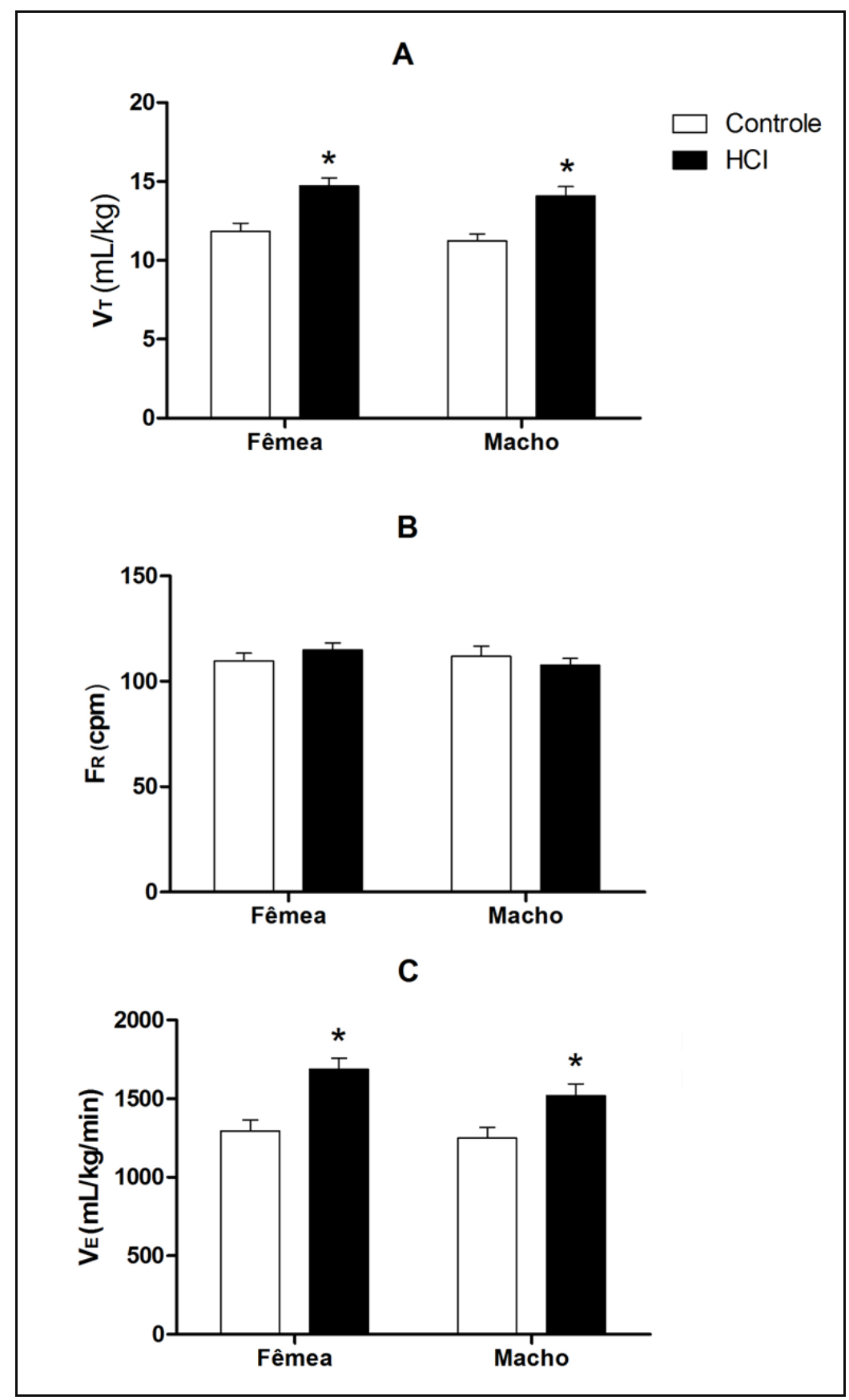

Figura 12. Parâmetros respiratórios basais nas fêmeas $(n=24)$ e machos $(n=18)$ submetidos à HCI em relação ao seu respectivo controle fêmeas $(n=28)$ e machos $(n=15)$. A. Volume corrente médio $\left(V_{T}\right)$ B. Frequência respiratória média $\left(F_{R}\right) C$. Ventilação-total média $\left(V_{E}\right) .(*) p<0,05$

A duração da inspiração foi menor nas ratas submetidas à HCI comparados com

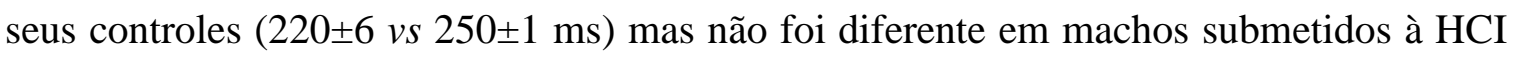
em relação ao seu controle ( $260 \pm 9$ vs $240 \pm 1$ ms). A duração da expiração não se alterou em ratos submetidos à HCI (fêmeas: $300 \pm 9$ vs $310 \pm 9$ ms; machos: $320 \pm 8$ vs $320 \pm 20$ ms) 
e na duração do ciclo respiratório (fêmeas: $510 \pm 10$ vs $560 \pm 10$ ms; machos: $570 \pm 10 v s$ $550 \pm 20 \mathrm{~ms}$ ). Não houve diferenças entre os grupos de machos e fêmeas nos parâmetros respiratórios analisados. Os dados estão apresentados na figura 13.

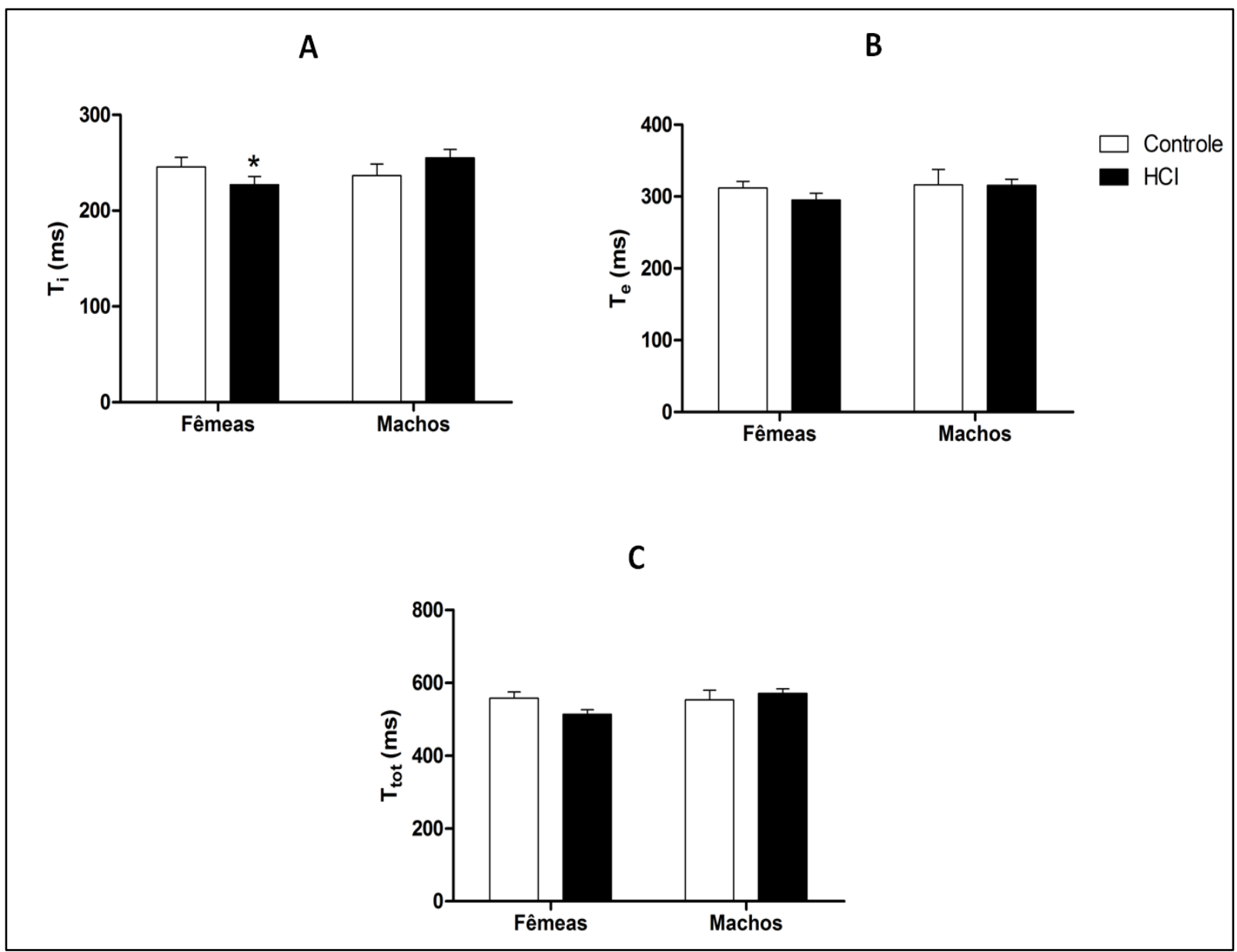

Figura 13. Parâmetros respiratórios basais nas fêmeas $(n=24)$ e machos $(n=18)$ jovens submetidos à HCI em relação ao seu respectivo controle fêmeas $(n=28)$ e machos $(n=15)$. A. $T_{i}$, tempo médio de inspiração (ms) B. $T_{e}$, tempo médio de expiração $(\mathrm{ms})$ C. $\mathrm{T}_{\text {tot }}$, tempo médio de duração do ciclo respiratório. $\left.{ }^{*}\right) \mathrm{p}<0,05$ 


\subsubsection{Parâmetros cardiovasculares de ratas adultas submetidas à HCI.}

As ratas jovens submetidas à HCI apresentaram aumento na pressão arterial semelhante aos machos, o que aparentemente se devia ao fato destas ratas serem sexualmente imaturas e não apresentarem variações hormonais, como ocorre com ratas adultas (Poletini e cols., 2003). Levando em conta essa informação, foi realizado um grupo experimental de ratas adultas submetidas à HCI por 35 dias. A duração do protocolo de HCI precisa ser mais longa para animais adultos como relatado em experimentos de Zoccal (2007), uma vez que nesta fase eles parecem ser menos sensíveis à hipóxia.

O nosso principal objetivo neste protocolo foi verificar, de modo geral, os efeitos da HCI sobre os parâmetros cardiovasculares de fêmeas adultas, sexualmente maduras. A análise das células do epitélio vaginal, por meio do esfregaço vaginal, foi feita para confirmar que as ratas adultas eram sexualmente maduras e estavam sobre influência dos hormônios sexuais. As ratas utilizadas neste estudo apresentavam variações no ciclo estral, pois foram observadas variações nas fases do ciclo durante o experimento. Embora o ciclo estral de ratas adultas influencie alguns parâmetros fisiológicos (Takezawa e cols., 1994) é comum agrupar as fêmeas adultas intactas em estudos envolvendo variáveis cardiovasculares (Reckelhoff e cols., 1999; Xue e cols., 2007). A fim de comparar os efeitos da HCI nos parâmetros cardiovasculares de fêmeas e machos adultos, utilizamos dados dos experimentos com machos adultos, realizados anteriormente em nosso laboratório (Zoccal e cols., 2007a; Zoccal e cols. 2007b).

Os animais submetidos à HCI apresentaram aumento significativo na PAM em relação ao seu respectivo grupo controle, fêmeas $(110 \pm 1$ vs $104 \pm 1 \mathrm{mmHg})$ e machos (114 \pm 2 vs $104 \pm 1 \mathrm{mmHg}$ ). Da mesma forma, foi observado aumento na FC em ambos os 
grupos submetidos à HCI em relação ao seu respectivo controle, fêmeas (400 \pm 6 vs 376 \pm 5 bpm) e machos ( $383 \pm 6$ vs $356 \pm 6$ bpm), figura 14 .

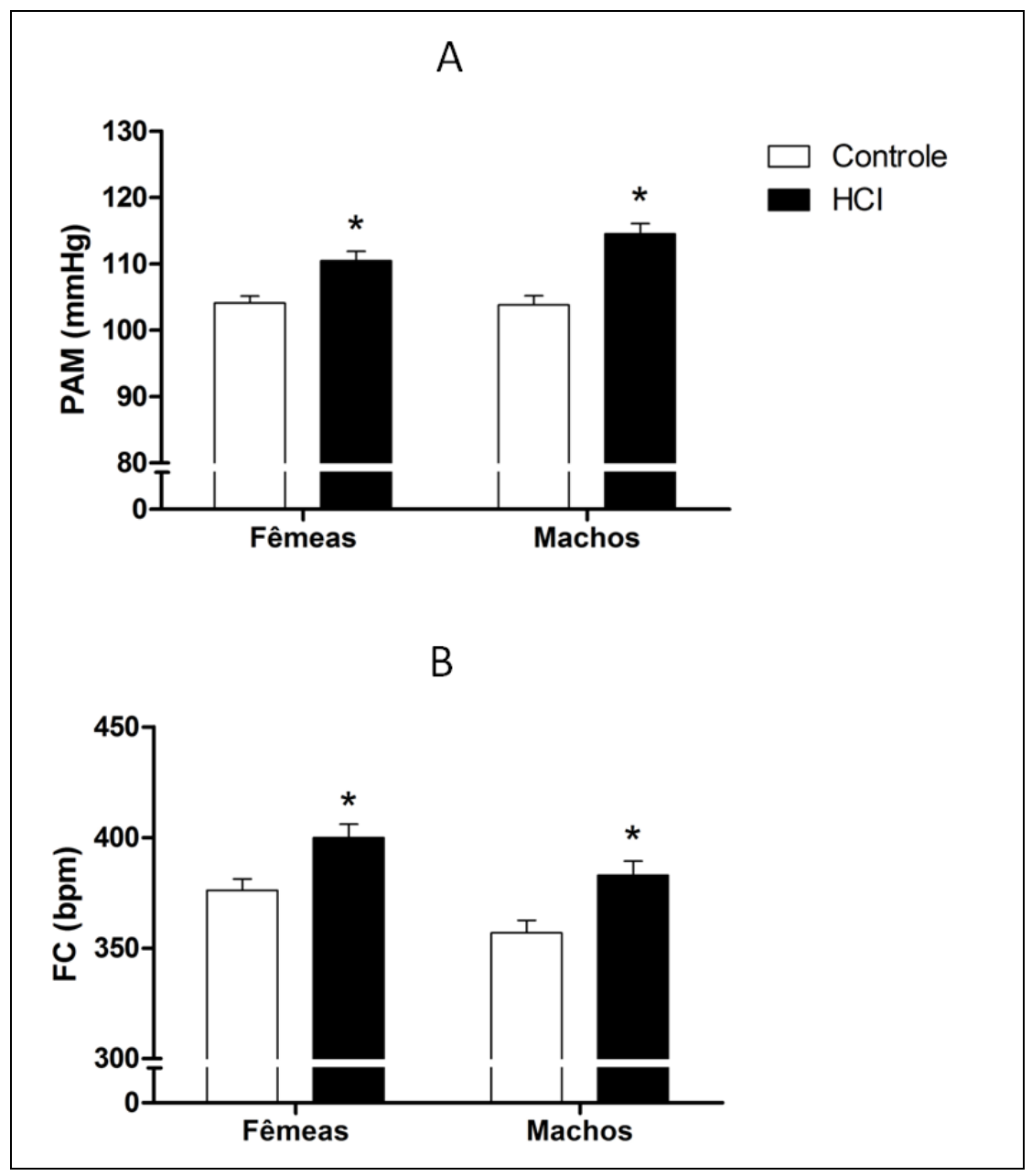

Figura 14. Parâmetros cardiovasculares em ratos adultos submetidos à HCI. A. Pressão arterial média (PAM) de fêmeas (n=27) e machos ( $\mathrm{n}=41)$ adultos submetidos à HCI em relação ao seu controle fêmeas $(n=26)$ e machos (n=38). B. Frequência cardíaca média $(\mathrm{FC})$ de ratos submetidos à HCI em relação ao seu respectivo controle. Os dados de PAM e FC relacionados aos machos adultos foram obtidos por experimentos realizados anteriormente pelo nosso laboratório (Zoccal e cols., 2007a; Zoccal e cols., 2007b). (*)p<0,05

\subsubsection{Parâmetros respiratórios basais de ratas adultas submetidas à HCI}

O volume corrente das ratas submetidas à $\mathrm{HCI}$ foi semelhante ao grupo controle, respectivamente $(7,8 \pm 0,4$ vs $8,1 \pm 0,3 \mathrm{ml} / \mathrm{kg})$. A frequência respiratória também foi similar 
entre os grupos HCI e controle (94 \pm 3 vs $102 \pm 3 \mathrm{cpm})$. Não foi observado alterações na ventilação-minuto de ratas submetidas à HCI em relação ao seu grupo controle $(779 \pm 44$ vs $796 \pm 47 \mathrm{ml} / \mathrm{kg} / \mathrm{min})$, como mostra a figura 15 .

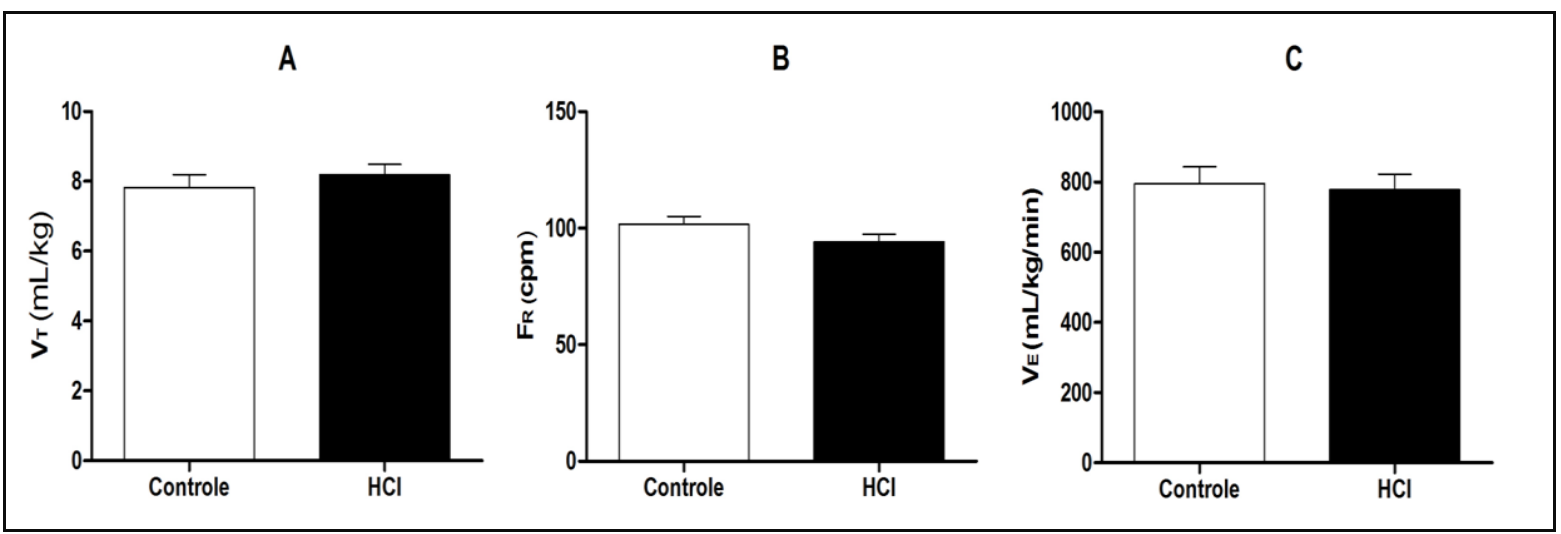

Figura 15. Parâmetros respiratórios de fêmeas adultas submetidas à $\mathrm{HCI}(\mathrm{n}=27)$ em relação ao grupo controle $(n=26)$. A. Volume corrente médio $\left(\mathrm{V}_{\mathrm{T}}\right)$ B. Frequência respiratória média $\left(\mathrm{F}_{\mathrm{R}}\right) \mathbf{C}$. Ventilação-total média $\left(\mathrm{V}_{\mathrm{E}}\right)$.

A duração do ciclo respiratório foi significativamente maior nas ratas submetidas

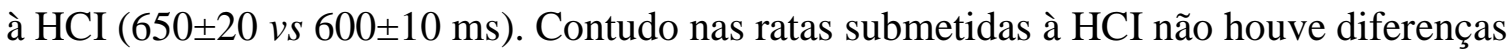

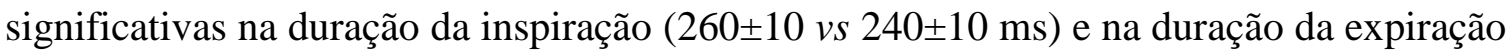

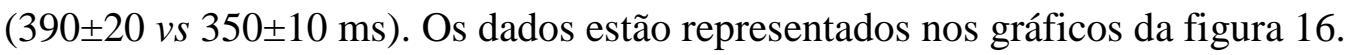




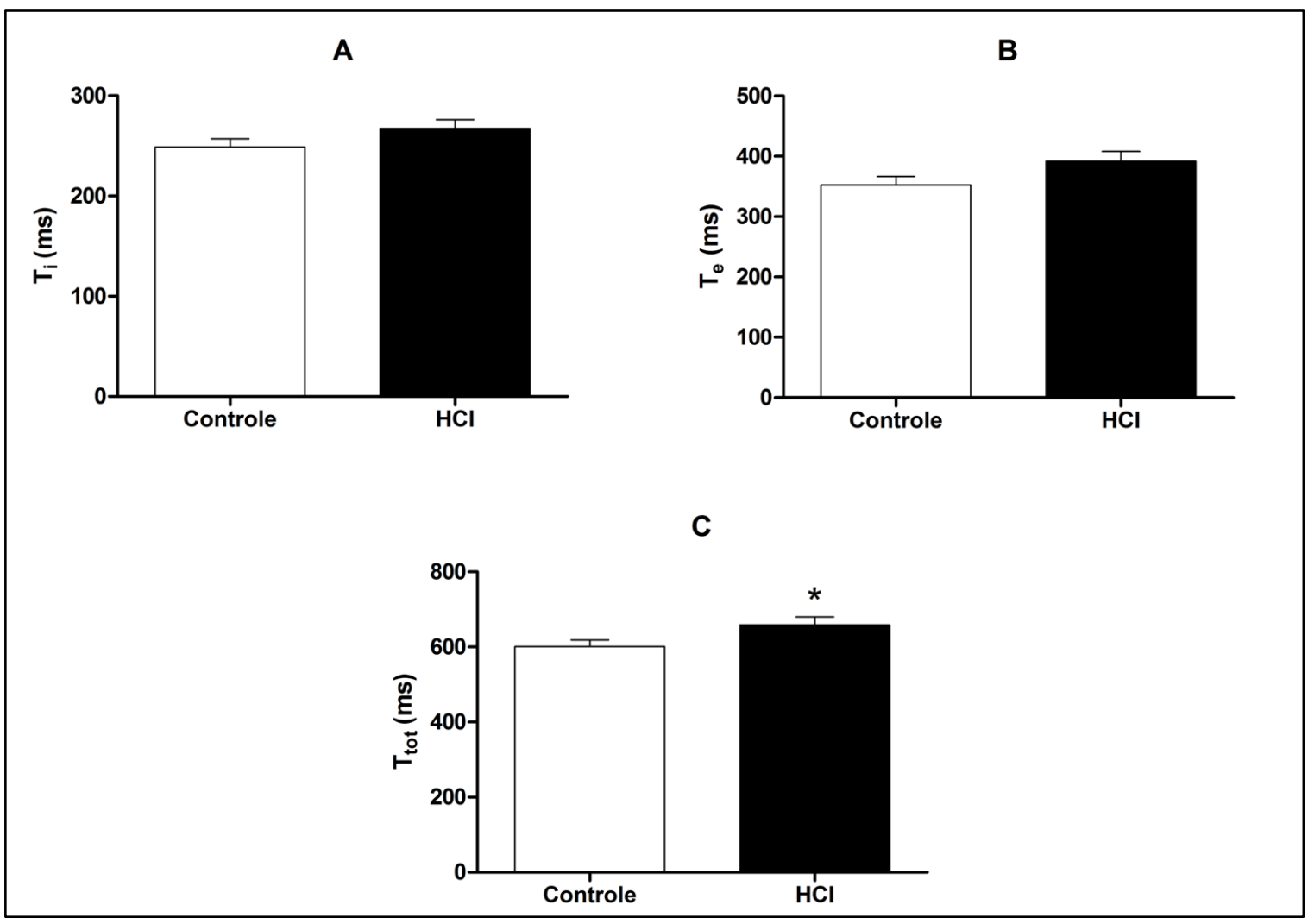

Figura 16. Parâmetros respiratórios basais nas fêmeas adultas submetidas à HCI $(n=27)$ em relação ao seu respectivo controle (n=26) A. Tempo de inspiração médio (s) B. Tempo médio de expiração (s) C. Tempo médio de duração do ciclo respiratório. (*)p $<0,05$

\subsection{Experimentos realizados na preparação in situ}

\subsubsection{Padrão respiratório basal de fêmeas submetidas à HCI}

As fêmeas jovens submetidas à HCI apresentaram alterações no padrão respiratório basal. A frequência respiratória das fêmeas submetidas à HCI foi maior do que o seu respectivo controle $(0,24 \pm 0,02$ vs $0,18 \pm 0,02 \mathrm{~Hz})$. Além disso, a duração da inspiração foi menor nas fêmeas submetidas à HCI em relação ao controle $(1,1 \pm 0,05$ vs $1,6 \pm 0,01 \mathrm{~s}) \mathrm{e}$ 
não houve alterações significativas na duração da expiração nas fêmeas submetidas à HCI em relação ao controle $(3,2 \pm 0,32$ vs 4,0 $\pm 0,34$ s). Os dados estão apresentados na figura 17.

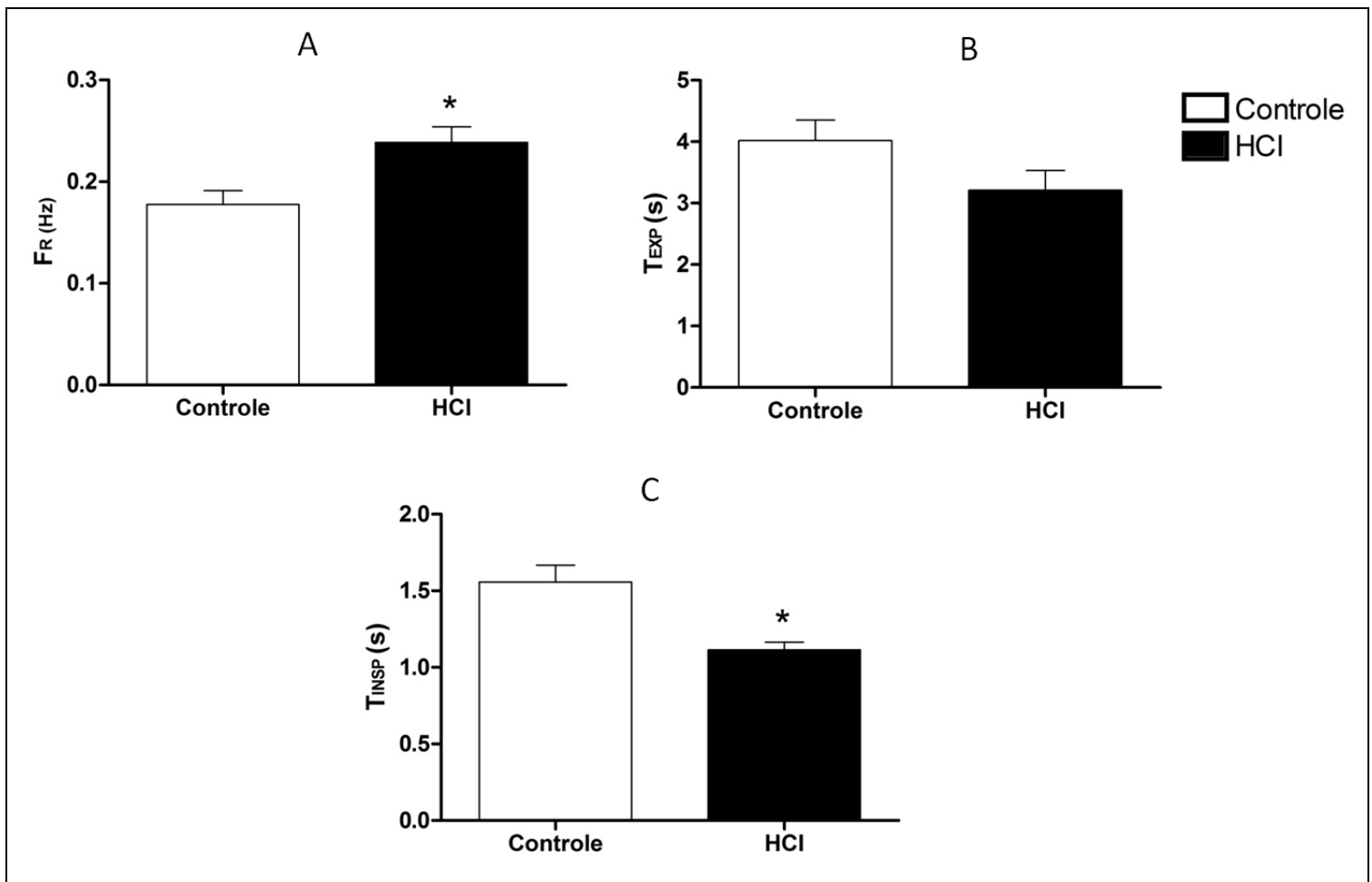

Figura 17. Parâmetros respiratórios na preparação coração-tronco cerebral isolados. A. Frequência respiratória nas fêmeas submetidas à $\mathrm{HCI}(\mathrm{n}=21)$ e controle $(\mathrm{n}=13)$. B. duração da expiração nas fêmeas submetidas à HCI e controle. C. Duração da inspiração nas fêmeas submetidas à HCI e controle. $\left(^{*}\right)$ p<0,05 
O registro do padrão respiratório basal de um animal representativo de cada grupo esta apresentado na figura 18.

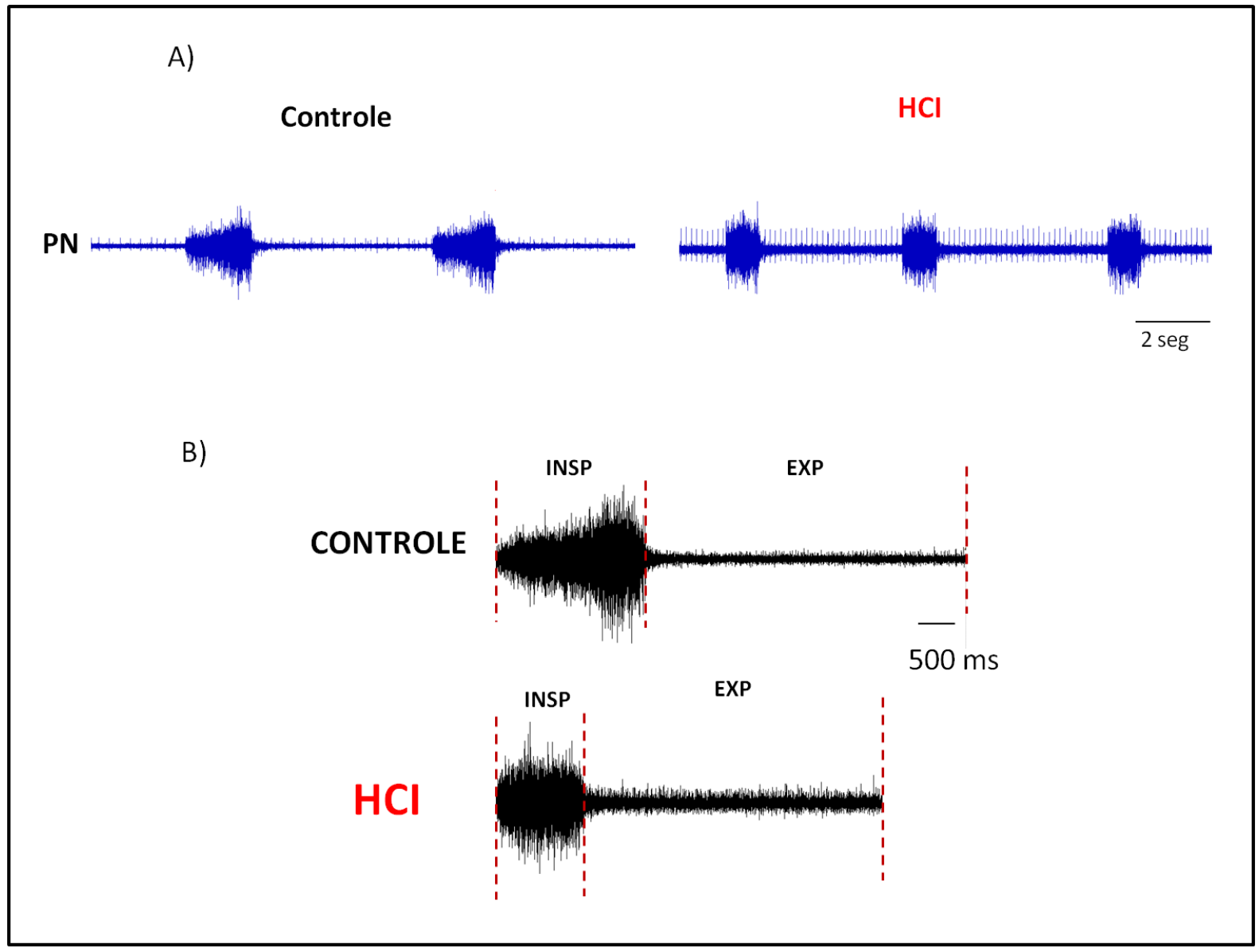

Figura 18. Padrão respiratório de ratas jovens submetidas à $\mathrm{HCI}(\mathrm{n}=21)$ e controle $(\mathrm{n}=13)$. A. Registros do nervo frênico de uma rata representativa do grupo controle e HCI. B. Média de 10 ciclos respiratórios (10 bursts do nervo frênico) de uma rata representativa do grupo controle e HCI.

\subsubsection{Atividade simpática basal em fêmeas submetidas à HCI}

Durante os experimentos foi possível obter o índice da atividade simpática a partir de registros do nervo simpático torácico de alguns animais. As ratas submetidas à HCI 
não apresentaram aumentos significativos na atividade simpática basal em relação ao controle (20 \pm 2 vs 14,8 $\pm 0,3 \%$, respectivamente). Os dados agrupados estão apresentados na figura 19.

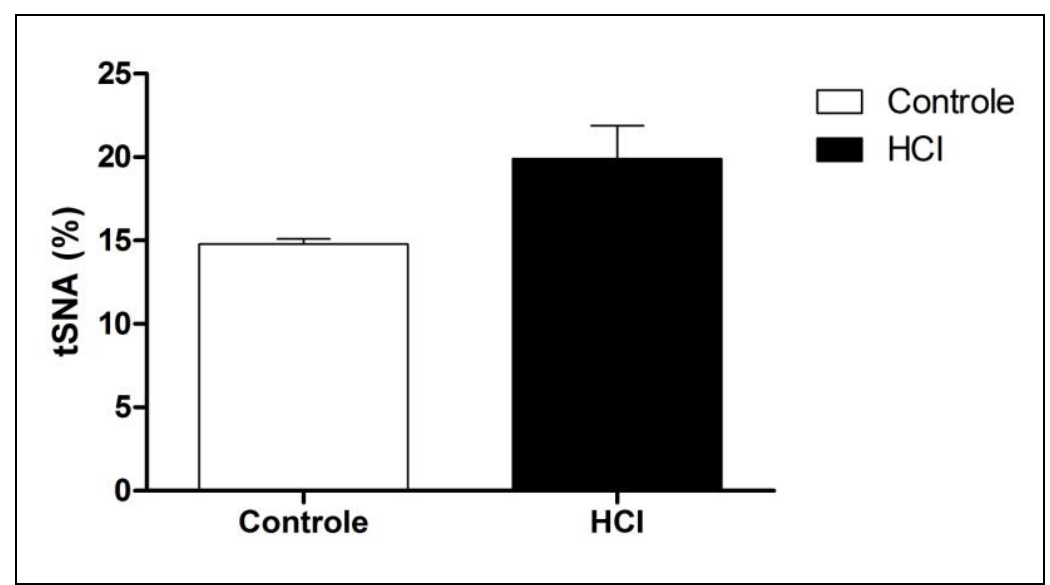

Figura 19. Média da atividade simpática basal nas fêmeas submetidas à HCI $(n=6)$ e controle $(n=4)$, $\mathrm{p}=0.07$.

Um exemplo de registro da atividade simpática de uma rata submetida à HCI e de uma rata controle pode ser visualizado da figura 20. 


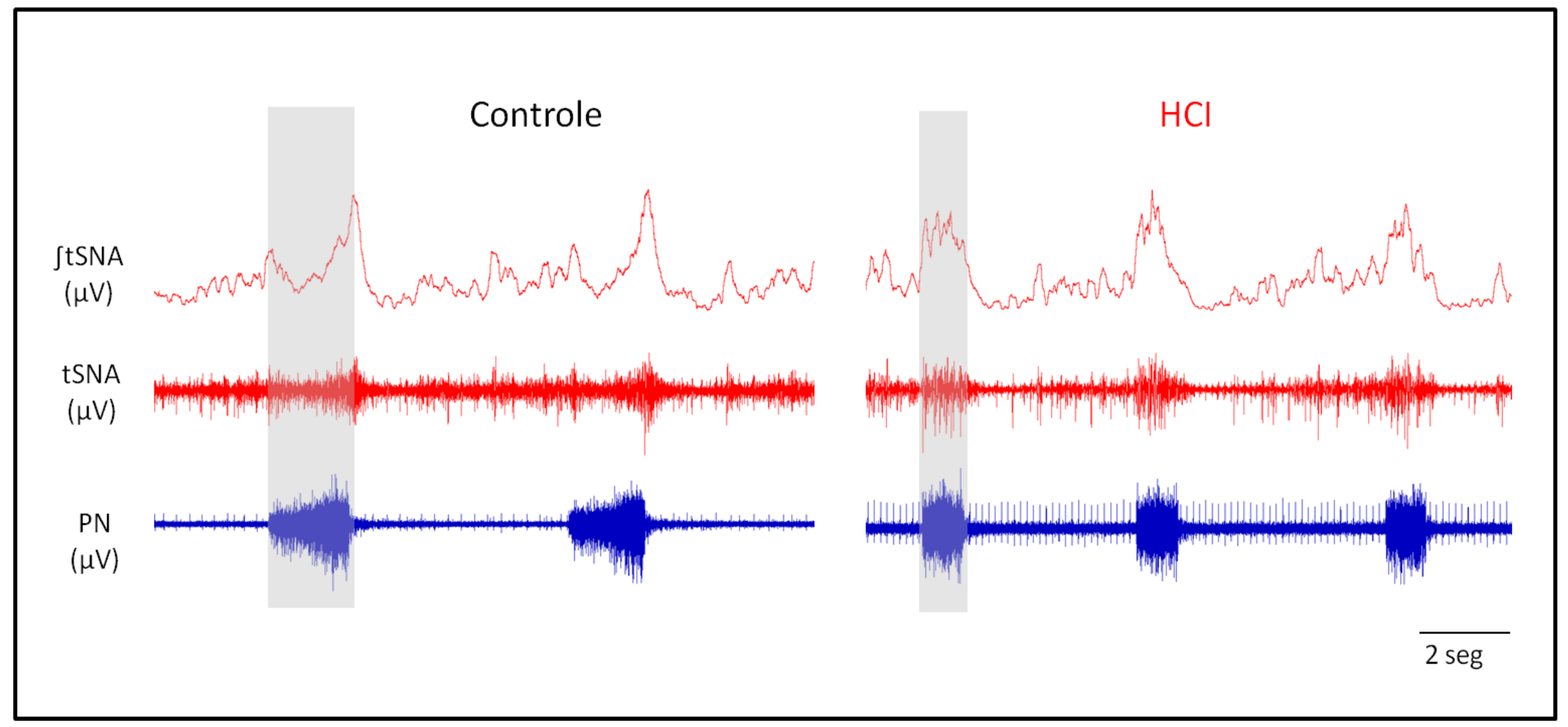

Figura 20. Registro da atividade simpática e respiratória de uma fêmea representativa do grupo controle e do grupo HCI. Observe que o padrão respiratório está alterado na fêmea submetida à HCI, assim como a distribuição da atividade simpática durante essa fase do ciclo respiratório. 


\subsubsection{Acoplamento simpático-respiratório em fêmeas submetidas à HCI}

As fêmeas jovens submetidas à HCI apresentaram alterações no acoplamento simpático-respiratório em relação ao controle. As fêmeas submetidas à HCI $(\mathrm{n}=6)$ apresentaram aumento da atividade simpática durante a fase inspiratória $(66 \pm 4$ vs $45 \pm 7 \%$ tSNA) quando comparadas com o seu respectivo controle (n=4). Não foram observadas alterações significativas na atividade simpática na fase expiratória inicial $(32 \pm 3 v s \quad 35 \pm 2 \%$ tSNA) e na fase expiratória final (40 1 vs $31 \pm 2 \%$ tSNA) entre as fêmeas submetidas à HCI em relação ao grupo controle respectivamente. Os dados agrupados podem ser visualizados na figura 21 .

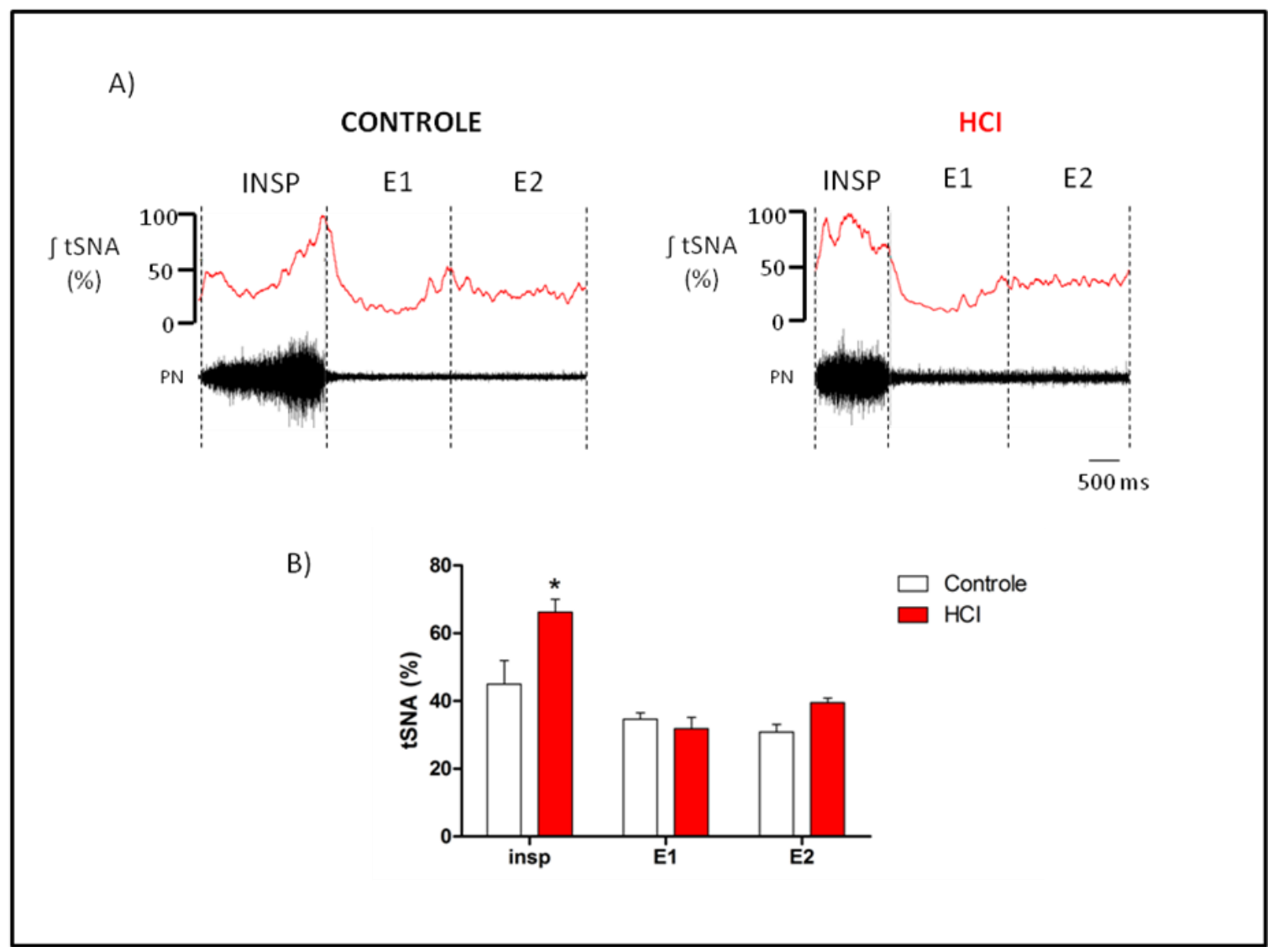

Figura 21. Acoplamento simpático-respiratório em fêmeas submetidas à HCI. A. Média da atividade simpática e do nervo frênico de 10 ciclos respiratórios de um animal representativo do grupo controle e HCI. B. Média dos valores de atividade simpática durante cada fase do ciclo respiratório. $(*)$ p $<0,05$ 
5.3. Concentração plasmática de hormônios sexuais em fêmeas submetidas à HCI

5.3.1. Concentração plasmática de progesterona em fêmeas jovens submetidas à HCI.

A concentração plasmática de progesterona foi menor em ratas jovens submetidas à HCI em relação ao seu controle $(41,6 \pm 12$ vs $85,7 \pm 16 \mathrm{ng} / \mathrm{ml})$. Os dados estão apresentados na figura 22.

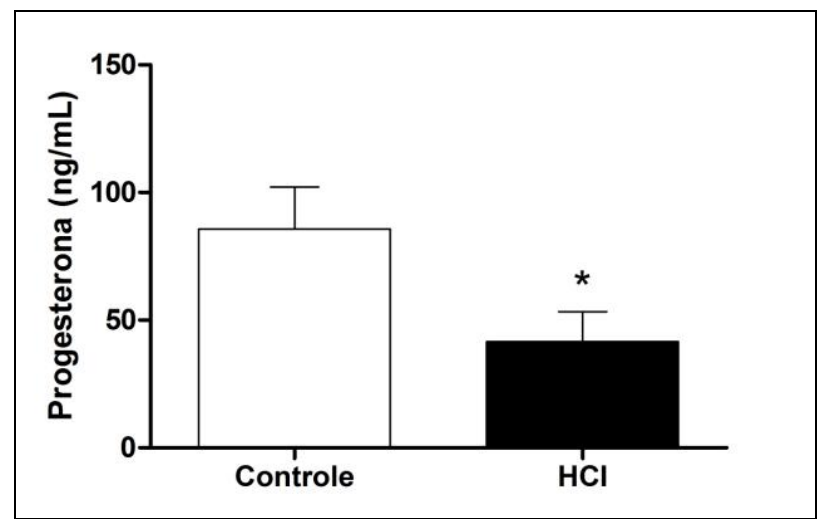

Figura 22. Progesterona plasmática média em ratas submetidas à HCI $(n=28)$ em relação ao seu respectivo controle $(\mathrm{n}=23) .(*) \mathrm{p}<0,05$

5.3.2. Concentração plasmática de estradiol em fêmeas jovens submetidas à HCI.

Não houve alteração na concentração plasmática de estradiol em nas ratas submetidas à HCI em relação ao seu respectivo controle $(80,9 \pm 8,7$ vs $80,6 \pm 8 \mathrm{pg} / \mathrm{ml})$. Os dados estão sumarizados na figura 23. 


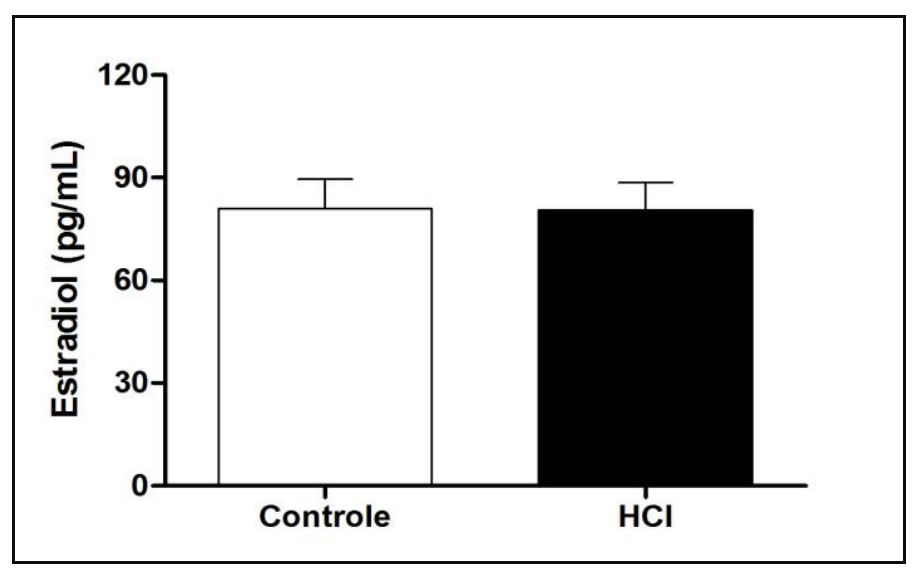

Figura 23. Estradiol plasmático médio nas fêmeas submetidas à HCI $(n=22)$ em relação ao seu respectivo controle $(n=21)$.

5.3.3. Concentração plasmática de LH nas fêmeas jovens submetidas à HCI

Não foi observado diferenças na concentração plasmática de LH nas ratas submetidas à HCI comparadas com seu respectivo controle $(0,29 \pm 0,03$ vs $0,34 \pm 0,05$ ng/ml ), figura 24 .

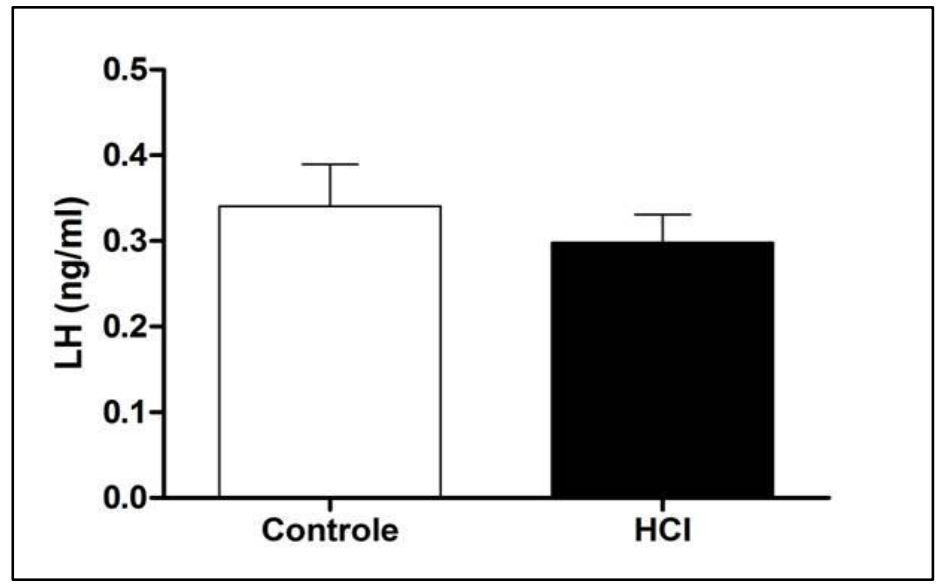

Figura 24. LH plasmático em ratas $(n=29)$ submetidas à HCI em relação ao seu respectivo controle $(n=24)$. 
5.3.4. Concentração plasmática de corticosterona em fêmeas jovens submetidas à $\mathrm{HCI}$

A concentração de corticosterona plasmática não foi significativamente diferente em ratas submetidas à HCI em relação ao seu controle (70 \pm 10 vs $60 \pm 10 \mathrm{ng} / \mathrm{ml})$. Os dados estão sumarizados na figura 25.

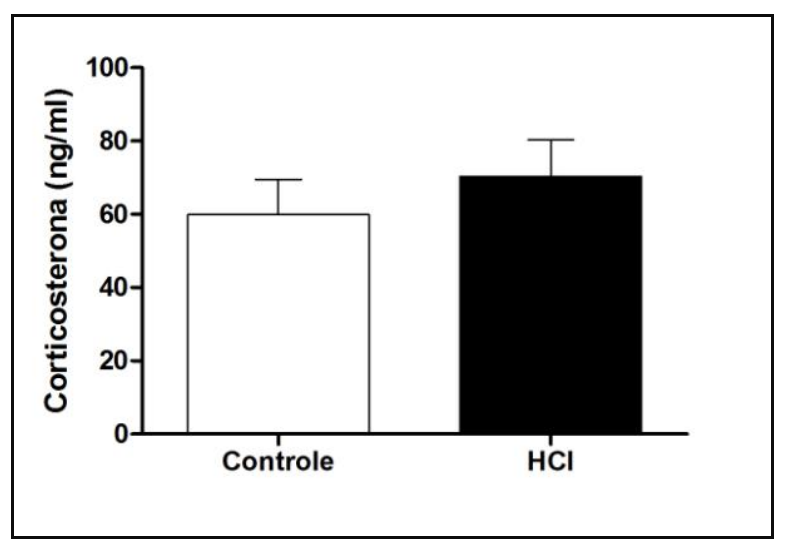

Figura 25. Corticosterona plasmática média em ratas $(n=29)$ submetidas à HCI em relação ao seu respectivo controle $(n=25)$.

\subsubsection{Concentração plasmática de estradiol em fêmeas adultas submetidas à HCI}

As concentrações hormonais em ratas adultas foram analisadas especificamente para cada fase do ciclo estral em que elas se encontravam no dia do registro das variáveis cardiovasculares. As ratas submetidas à HCI que estavam no estro no dia do registro não apresentaram alterações nas concentrações de estradiol em relação ao seu respectivo controle $(150 \pm 37$ vs $121 \pm 26 \mathrm{pg} / \mathrm{mL})$. As ratas adultas submetidas à HCI que estavam no diestro 1 , também não apresentaram alterações nas concentrações hormonais de estradiol em relação ao controle $(77 \pm 13$ vs $100 \pm 6 \mathrm{pg} / \mathrm{mL})$ bem como as 
ratas que estavam em diestro $2(93 \pm 11$ vs $88 \pm 16$ pg/mL). Os dados estão apresentados na figura 26.

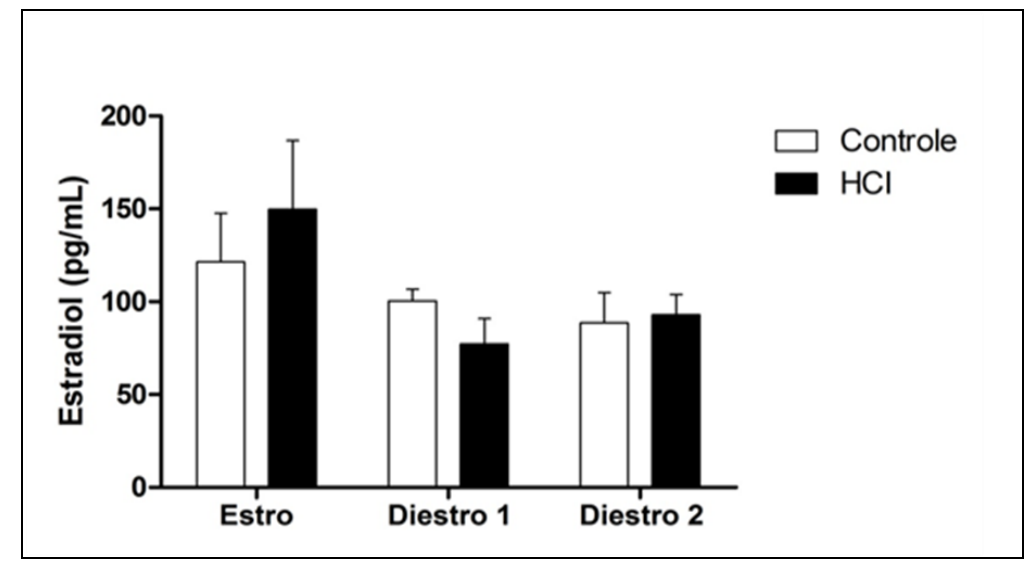

Figura 26. Concentração plasmática de estradiol em ratas adultas submetidas à HCI e controle de acordo com a fase do ciclo estral no dia do registro. (Estro HCI, $n=7$; Estro Controle, $n=8$; Diestro $1 \mathrm{HCI}, \mathrm{n}=10$; Diestro 1 controle, $n=10$; Diestro 2 HCI, $n=9$; Diestro 2 controle, $n=8$ ).

5.3.6. Concentração plasmática de progesterona em fêmeas adultas submetidas à $\mathrm{HCI}$

As ratas adultas submetidas à HCI não apresentaram alterações na concentração plasmática de progesterona em relação ao seu respectivo controle no estro $(89 \pm 59$ vs $89 \pm 23 \mathrm{ng} / \mathrm{mL})$ no diestro $1(66 \pm 14$ vs $107 \pm 26)$ ou no diestro $2(167 \pm 32$ vs $181 \pm 39 \mathrm{ng} / \mathrm{mL}$ ). Os dados estão sumarizados na figura 27 . 


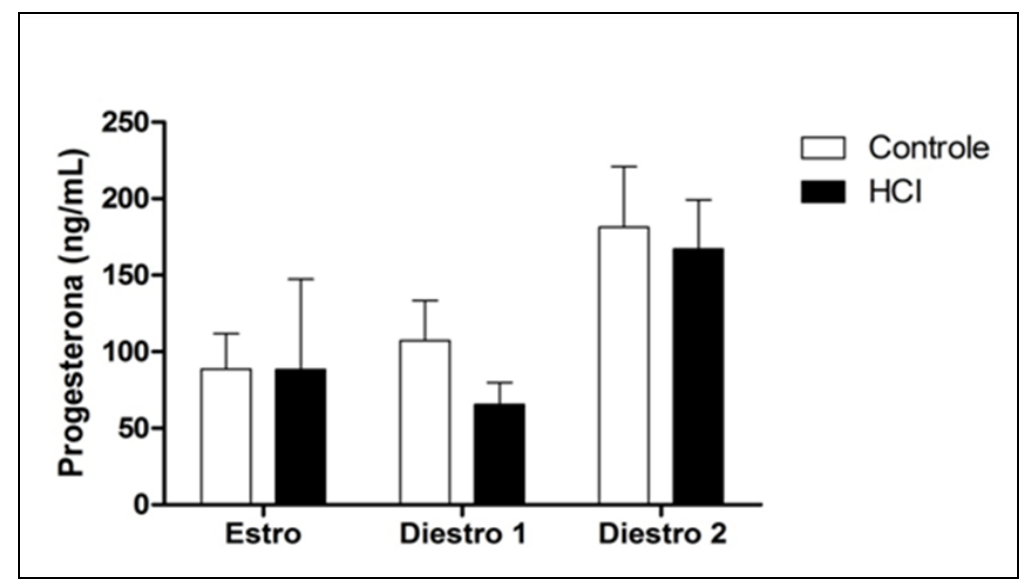

Figura 27. Concentração plasmática de progesterona em ratas adultas submetidas à HCI e controle de acordo com a fase do ciclo estral no dia do registro. (Estro HCI, n= 7; Estro Controle, n=9; Diestro 1 HCI, n=9; Diestro 1 controle, $n=9$; Diestro 2 HCI, n=9; Diestro 2 controle, $n=6$ ). 


\section{DISCUSSÃO}

6.1. Alterações cardiovasculares em ratas submetidas à HCI

Ao analisarmos a evolução da PAS durante o desenvolvimento do animal observamos que ocorre um aumento da PAS com o crescimento, contudo o aumento foi maior nos ratos machos submetidos à $\mathrm{HCI}$, como observado em estudos anteriores do nosso laboratório (Zoccal e cols., 2009a). As fêmeas jovens apresentaram aumento da PAS durante o crescimento, assim como os machos. Contudo, o aumento da PAS em ratas submetidas à $\mathrm{HCI}$ não foi significativamente maior do que o aumento no grupo controle, diferente do que ocorreu com os machos submetidos à HCI. O número de fêmeas utilizadas neste protocolo, onde a aferição da PAS foi feita de maneira indireta por meio pletismografia de cauda, pode não ter sido suficiente para evidenciar as diferenças no nível de PAS das ratas submetidas à HCI.

Nos estudos realizados com medida direta de pressão arterial, as fêmeas submetidas à HCI apresentaram aumento na PAM, PAS, PAD e FC semelhantes aos machos submetidos à HCI. Esses dados mostram que as ratas submetidas à HCI não apresentam resistência no desenvolvimento da hipertensão arterial. Possivelmente, os hormônios sexuais nas ratas jovens ou nas ratas adultas não são suficientes para promover a proteção destes animais contra o aumento de pressão arterial após a HCI.

Os mecanismos pela qual os hormônios sexuais, como estrógeno e progesterona, promovem a resistência das fêmeas contra os aumentos de pressão arterial ainda são especulativos (Reckelhoff, 2004). O dimorfismo sexual encontrado em modelos experimentais de hipertensão pode envolver o controle do estresse oxidativo (Lopez-Ruiz e cols., 2008). Estudos sugerem que o estrógeno pode, por exemplo, modular a produção de óxido nítrico neural (nNO), composto conhecido por reduzir a atividade simpática 
(Patel e cols., 2001; Xue e cols., 2009). Além disso, o estrógeno reduz a atividade de enzimas pró-oxidantes, como a NADPH-oxidase, promovendo a diminuição do estresse oxidativo no organismo, o que pode contribuir para níveis mais baixos de pressão arterial (Xue e cols., 2007).

Os hormônios sexuais também podem modular a atividade do sistema reninaangiotensina (SRA). Os andrógenos, como a testosterona, influenciam positivamente o SRA, aumentando a produção de ANG II. O aumento de ANG II, por sua vez, promove aumento na reabsorção tubular de sódio e vasoconstrição, fatores que contribuem para o aumento do volume extracelular e da pressão arterial (Reckelhoff, 2001). Estudos com ratos SHR mostram o efeito facilitador da testosterona, onde machos castrados apresentam níveis menores de pressão arterial do que machos intactos (Reckelhoff e cols., 1998). Os mecanismos que geram a hipertensão são diferentes entre os modelos experimentais e estes mecanismos são susceptíveis a ação dos hormônios sexuais, uma vez que as fêmeas apresentam resistência ao desenvolvimento da hipertensão arterial.

Evidências experimentais sugerem que os mecanismos envolvidos na hipertensão em ratos submetidos à HCI são, principalmente, de origem neural (Zoccal e cols., 2009, Zoccal e cols., 2008). Nossos resultados sugerem os mecanismos que promovem elevação da PAM nas fêmeas submetidas à HCI não são influenciados pelos hormônios sexuais, diferente do que ocorre em outros modelos experimentais. Os fatores responsáveis pela hipertensão em animais submetidos à HCI ainda não foram completamente esclarecidos. Evidências sugerem que neurônios respiratórios bulbares podem ser responsáveis pela alteração no acoplamento simpático-respiratório causando aumento na atividade simpática e consequente hipertensão (Moraes e cols., 2012). Portanto, a elevação da PA pode ser secundária às alterações no padrão respiratório e a atividade simpática de animais submetidos à HCI (Zoccal \& Machado, 2011). 
6.2. Alterações respiratórias em ratas submetidas à HCI no modelo do animal acordado

Alterações no padrão respiratório em ratos submetidos à HCI foram demonstradas por nosso laboratório utilizando a preparação in situ. Os ratos submetidos à HCI apresentam expiração ativa, observada pelo aumento na atividade do nervo abdominal e diminuição da atividade pós-inspiratória do nervo vago, que pode indicar diminuição de resistência das vias aéreas superiores durante a pós-inspiração (Zoccal e cols., 2008). Contudo, ainda não foram descritas as diferenças no padrão respiratório causadas pela HCI em animais acordados.

Os nossos resultados mostram alterações no padrão respiratório, o qual foi registrado por meio do método de pletismografia de corpo inteiro, em machos e fêmeas jovens submetidas à $\mathrm{HCI}$. Os aumentos no $\mathrm{V}_{\mathrm{T}}$ e na $\mathrm{V}_{\mathrm{E}}$ observados nos ratos submetidos à HCI sugere que eles sofreram alterações no padrão respiratório. Não houve diferenças entre os sexos nas alterações causadas pela HCI, pois as ratas jovens apresentaram alterações respiratórias semelhantes às encontradas nos machos.

Em um estudo anterior foram apontadas diferenças entre os sexos nas alterações ventilatórias, onde as fêmeas submetidas à $\mathrm{HCI}$ não apresentaram aumento no $\mathrm{V}_{\mathrm{T}} \mathrm{e}$ na $\mathrm{V}_{\mathrm{E}}$ como os machos, contudo o protocolo de HCI utilizado pelos autores foi diferente do proposto no nosso estudo (Skelly e cols., 2011). Outro estudo mostrou que o estradiol, principal estrogênio feminino, pode influenciar a atividade contrátil do músculo genioglosso em ratas submetidas à HCI. Este trabalho sugere que, devido à presença de estradiol, as vias aéreas superiores de ratas são menos susceptíveis a colapsarem (Liu e cols., 2009). Este fenômeno parece estar presente em humanos, onde homens e mulheres são diferentes em relação ao controle das vias aéreas superiores durante o sono (Trinder e cols., 1997). 
A HCI promove alterações na ventilação basal e na resposta à hipóxia em animais neonatos, além de promover maior sensibilização do corpúsculo carotídeo à hipóxia (Peng e cols., 2004). A sensibilização à hipóxia promovida pela HCI é diferente entre idades, sendo menor em ratos adultos quando comparado com neonatos (Pawar e cols., 2008). Apesar dos efeitos da HCI no padrão respiratório de ratos jovens, não observamos diferenças entre sexos em nenhum parâmetro respiratório analisado na condição experimental do animal acordado.

As fêmeas adultas submetidas à HCI não apresentaram alterações respiratórias como as encontradas em ratas jovens. Os parâmetros respiratórios de ratas adultas submetidas à HCI permaneceram semelhantes aos do grupo controle, contudo não é possível afirmar se essa ausência de alterações estava relacionada ao sexo ou a idade, pois não possuímos o registro dos parâmetros respiratórios dos machos adultos para a comparação.

A pletismografia de corpo inteiro utilizada em nossos experimentos não é um método tão preciso para este tipo de análise, pois envolve um grande número de variáveis, como temperatura corpórea e umidade do ar. Tendo em vista as limitações desta técnica, se fez necessária a utilização de uma abordagem complementar como a preparação coração-tronco cerebral isolados. Essa abordagem experimental permite o registro direto de nervos respiratórios, como o nervo frênico, índice da atividade inspiratória. 
6.3. Alterações no padrão respiratório basal de ratas submetidas à HCI na preparação in situ

As ratas submetidas à HCI apresentaram alterações significantes no padrão respiratório basal, tendo sido observado um aumento da frequência respiratória e redução na duração da inspiração. Estudos de Zoccal e cols. 2008, utilizando a mesma preparação, mostraram que os ratos machos submetidos à HCI não apresentam alterações na duração da inspiração ou da frequência respiratória basais sendo, portanto, diferente do que foi observado nas fêmeas. Contudo, os ratos machos apresentam alterações no padrão respiratório relacionadas à expiração, onde foi observado um aumento na atividade do nervo abdominal e redução do pico de atividade pós-inspiratória do nervo vago (Zoccal e cols., 2008).

Estudos de Holley e cols., 2012 mostraram que a resposta ventilatória à hipóxia em ratos é diferente entre os sexos, principalmente nos primeiros 15 dias de vida. A idade e sexo, portanto, podem ser fatores cruciais nas alterações ventilatórias causadas pela HCI. Além disso, episódios de hipóxia podem promover plasticidade de neurônios respiratórios, principalmente durante a fase neonatal (Reeves \& Gozal, 2005). A exposição à hipóxia durante esta fase altera as respostas respiratórias a um novo episódio de hipóxia na vida adulta em ratos e são diferentes entre machos e fêmeas, sugerindo uma plasticidade diferencial entre machos e fêmeas submetidos à hipóxia neonatal (Bavis e cols., 2004).

De acordo com os nossos resultados, podemos sugerir que existe uma plasticidade diferente entre machos e fêmeas submetidos à HCI. As fêmeas submetidas à HCI respondem com alterações no acoplamento simpático e respiratório principalmente durante a inspiração e os machos com alterações respiratórias durante a expiração. 


\subsection{Alterações no acoplamento-simpático respiratório de ratas submetidas à HCI}

As ratas submetidas à HCI apresentaram aumento na atividade simpática durante a inspiração, diferente dos ratos machos que quando submetidos ao mesmo protocolo apresentaram aumento na atividade simpática durante a expiração (Zoccal, 2008). Provavelmente as alterações no padrão respiratório das ratas submetidas à HCI, predominantemente durante a inspiração, são as responsáveis pelo aumento da atividade simpática nesta fase do ciclo respiratório. Em ratos jovens machos, o aumento da atividade simpática está relacionada com o aumento da atividade inspiratória do nervo abdominal, na fase final da expiração (Zoccal e cols., 2008). Deste modo, os resultados apontam uma diferença entre os sexos nas alterações do acoplamento simpáticorespiratório de animais submetidos à HCI.

As alterações no acoplamento simpático-respiratório não são exclusivas de animais submetidos à HCI, pois também foram observadas em ratos SHR (Simms e cols., 2009) e no modelo de hipertensão angiotensina II-sal (Toney e cols., 2010). Conjuntamente todas essas evidências sustentam a hipótese de que a atividade respiratória possui um papel importante na modulação da atividade simpática e no desenvolvimento da hipertensão arterial (Zoccal e cols., 2009b; Simms e cols., 2010).

\subsection{Concentração de hormônios sexuais no plasma de ratas submetidas à HCI}

A maioria dos estudos em pesquisa básica é feita utilizando preferencialmente animais machos. A razão mais evidente é que as fêmeas possuem variação hormonal durante os 4 dias de ciclo estral, o que por sua vez pode influenciar as respostas fisiológicas estudadas em cada fase do ciclo. Contudo, a preferência pela utilização de 
machos nas pesquisas pode negligenciar as diferenças entre os sexos nos diversos parâmetros fisiológicos (ter Horst e cols., 2012).

Em situações de estresse, as ratas podem sofrer alterações na concentração de hormônios sexuais circulantes e em algumas situações a resposta é diferente dos machos (Luine e cols., 2007; Traslavina \& Franci, 2011). Além disso, situações de HCI podem sensibilizar o eixo hipotálamo-hipófise-adrenal, aumentando à secreção de ACTH, como ocorre em situações de estresse (Ma e cols., 2008). A corticosterona plasmática é descrita como um indicador fisiológico de estresse em ratos e está elevada em ratos adultos submetidos à HCI (Zoccal e cols., 2007a). Levando em conta essas informações, investigamos a concentração de hormônios sexuais e de corticosterona no plasma de ratas submetidas à HCI.

A concentração de corticosterona no plasma não foi diferente nas ratas jovens submetidas à HCI como ocorre nos machos adultos. Um fator importante que deve ser levado em consideração é o período em que as coletas de sangue foram feitas, tendo em vista que a concentração de corticosterona sofre variações ao longo do dia. Neste caso as coletas foram feitas no período entre $11 \mathrm{H} 00$ e $17 \mathrm{H} 00$, o qual é relativamente extenso para a coleta desse hormônio, o que poderia explicar a grande variação nas concentrações encontradas neste estudo.

Foi observada uma alteração na concentração de progesterona plasmática de fêmeas jovens submetidas à HCI. A HCI promoveu redução de progesterona plasmática de ratas jovens, o que pode indicar a influencia da HCI no aumento natural de progesterona durante o desenvolvimento, principalmente na fase pré-púbere.

Durante os experimentos com ratas adultas, foi considerada a possibilidade de que a HCI pudesse alterar o ciclo estral das ratas, por ser considerada uma situação de estresse (Zoccal e cols., 2007). Portanto, além das dosagens hormonais, foi feito o acompanhamento do ciclo estral das ratas adultas nos últimos dias do protocolo. Houve 
variação nas fases do ciclo estral tanto no grupo de fêmeas submetidas à HCI, quanto de fêmeas mantidas em normóxia. Estes dados sugerem que as fêmeas adultas eram sexualmente maduras e que elas estavam sobre influência dos hormônios sexuais mesmo durante a HCI, o que se mostrou importante para a análise e interpretação dos nossos resultados.

Para estudar os efeitos do ciclo estral nos parâmetros fisiológicos é recomendado selecionar animais que possuam o ciclo regular de quatro dias (Donadio e cols., 2007), contudo esse procedimento não foi realizado durante os nossos experimentos. Neste caso, não foi possível avaliar a relação de cada fase do ciclo com os parâmetros cardiovasculares e respiratórios registrados nos nossos experimentos, pois não há evidências de que as fêmeas possuíam um ciclo regular de quatro dias. Além disso, não houve alteração na concentração plasmática de estradiol e progesterona plasmáticos nas ratas adultas submetidas à $\mathrm{HCI}$, indicando que as ratas estavam sobre uma influência hormonal semelhante à do grupo controle. Apesar desses fatores, as ratas adultas desenvolveram hipertensão arterial semelhante aos machos adultos submetidos ao mesmo protocolo. Esse conjunto de evidências indica que os hormônios sexuais não são suficientes para proteger as ratas contra o desenvolvimento da hipertensão promovido pela HCI. 


\section{CONCLUSÕES}

Concluímos que as ratas jovens e adultas não apresentam resistência ao desenvolvimento da hipertensão no modelo de HCI, pois desenvolvem níveis de hipertensão semelhante aos machos submetidos ao mesmo protocolo. Na preparação in situ foi observado que as ratas jovens submetidas à HCI desenvolvem alterações no padrão respiratório basal. Além disso, após a HCI as ratas jovens apresentaram alterações no acoplamento simpático-respiratório, caracterizado como o aumento da atividade simpática durante a inspiração, o que é diferente das alterações observadas em machos jovens submetidos ao mesmo protocolo. A partir destes resultados, podemos sugerir que embora fêmeas e machos submetidos à HCI desenvolvam um nível similar de hipertensão, os mecanismos envolvidos neste processo são diferentes entre os sexos. 


\section{REFERÊNCIAS BIBLIOGRÁFICAS}

Abdala AP, Rybak IA, Smith JC, Zoccal DB, Machado BH, St-John WM, et al. Multiple pontomedullary mechanisms of respiratory rhythmogenesis. Respir Physiol Neurobiol. 2009 Aug 31:19-25.

Barros RC, Bonagamba LG, Okamoto-Canesin R, de Oliveira M, Branco LG, Machado BH. Cardiovascular responses to chemoreflex activation with potassium cyanide or hypoxic hypoxia in awake rats. Auton Neurosci. 2002 May $31: 110-5$.

Bavis RW, Olson EB, Jr., Vidruk EH, Fuller DD, Mitchell GS. Developmental plasticity of the hypoxic ventilatory response in rats induced by neonatal hypoxia. J Physiol. 2004 Jun 1:645-60.

Behan M, Zabka AG, Thomas CF, Mitchell GS. Sex steroid hormones and the neural control of breathing. Respir Physiol Neurobiol. 2003 Jul 16:249-63.

Bixler EO, Vgontzas AN, Lin HM, Ten Have T, Rein J, Vela-Bueno A, et al. Prevalence of sleep-disordered breathing in women: effects of gender. $\boldsymbol{A} \boldsymbol{m} \boldsymbol{J}$ Respir Crit Care Med. 2001 Mar:608-13.

Braga VA, Soriano RN, Machado BH. Sympathoexcitatory response to peripheral chemoreflex activation is enhanced in juvenile rats exposed to chronic intermittent hypoxia. Exp Physiol. 2006 Nov:1025-31.

Caeiro XE, Mir FR, Vivas LM, Carrer HF, Cambiasso MJ. Sex chromosome complement contributes to sex differences in bradycardic baroreflex response. Hypertension. 2011 Sep:505-11.

Caplea A, Seachrist D, Daneshvar H, Dunphy G, Ely D. Noradrenergic content and turnover rate in kidney and heart shows gender and strain differences. $\boldsymbol{J}$ Appl Physiol. 2002 Feb:567-71.

Cowley AW, Jr., Monos E, Guyton AC. Interaction of vasopressin and the baroreceptor reflex system in the regulation of arterial blood pressure in the dog. Circ Res. 1974 Apr:505-14.

Dampney RA. Is the RVLM a key site for sex-related differences in blood pressure regulation? Focus on "sex differences in angiotensin signaling in bulbospinal neurons in the rat rostral ventrolateral medulla," by Wang et al. Am $\boldsymbol{J}$ Physiol Regul Integr Comp Physiol. 2008 Oct:R1147-8.

Donadio MV, Kunrath A, Corezola KL, Franci CR, Anselmo-Franci JA, Lucion AB, et al. Effects of acute stress on the day of proestrus on sexual behavior and ovulation in female rats: participation of the angiotensinergic system. Physiol Behav. 2007 Nov 23:591-600. 
Elias PC, Elias LL, Castro M, Antunes-Rodrigues J, Moreira AC. Hypothalamicpituitary-adrenal axis up-regulation in rats submitted to pituitary stalk compression. J Endocrinol. 2004 Feb:297-302.

Ely DL, Turner ME. Hypertension in the spontaneously hypertensive rat is linked to the Y chromosome. Hypertension. 1990 Sep:277-81.

Feldman JL, Ellenberger HH. Central coordination of respiratory and cardiovascular control in mammals. Annu Rev Physiol. 1988:593-606.

Fletcher EC, Lesske J, Culman J, Miller CC, Unger T. Sympathetic denervation blocks blood pressure elevation in episodic hypoxia. Hypertension. 1992 Nov:612-9.

Franchini KG, Krieger EM. Cardiovascular responses of conscious rats to carotid body chemoreceptor stimulation by intravenous KCN. J Auton Nerv Syst. 1993 Jan:639.

Granjeiro EM, Pajolla GP, Accorsi-Mendonca D, Machado BH. Interaction of purinergic and nitrergic mechanisms in the caudal nucleus tractus solitarii of rats. Auton Neurosci. 2009 Dec 3:117-26.

Haibara AS, Bonagamba LG, Machado BH. Sympathoexcitatory neurotransmission of the chemoreflex in the NTS of awake rats. Am J Physiol. 1999 Jan:R69-80.

Hayward CS, Kelly RP, Collins P. The roles of gender, the menopause and hormone replacement on cardiovascular function. Cardiovasc Res. 2000 Apr:28-49.

Holley HS, Behan M, Wenninger JM. Age and sex differences in the ventilatory response to hypoxia and hypercapnia in awake neonatal, pre-pubertal and young adult rats. Respir Physiol Neurobiol. 2012 Jan 15:79-87.

Kapur VK. Obstructive sleep apnea: diagnosis, epidemiology, and economics. Respir Care. 2010 Sep:1155-67.

Kara T, Narkiewicz K, Somers VK. Chemoreflexes--physiology and clinical implications. Acta Physiol Scand. 2003 Mar:377-84.

Kline DD. Chronic intermittent hypoxia affects integration of sensory input by neurons in the nucleus tractus solitarii. Respir Physiol Neurobiol. 2010 Nov 30:29-36.

Krieger EM. Neurogenic Hypertension in the Rat. Circ Res. 1964 Dec:511-21.

Liu YH, Huang Y, Shao X. Effects of estrogen on genioglossal muscle contractile properties and fiber-type distribution in chronic intermittent hypoxia rats. Eur $\boldsymbol{J}$ Oral Sci. 2009 Dec:685-90.

Lopez-Ruiz A, Sartori-Valinotti J, Yanes LL, Iliescu R, Reckelhoff JF. Sex differences in control of blood pressure: role of oxidative stress in hypertension in females. Am J Physiol Heart Circ Physiol. 2008 Aug:H466-74. 
Luine VN, Beck KD, Bowman RE, Frankfurt M, Maclusky NJ. Chronic stress and neural function: accounting for sex and age. J Neuroendocrinol. 2007 Oct:74351.

Ma S, Mifflin SW, Cunningham JT, Morilak DA. Chronic intermittent hypoxia sensitizes acute hypothalamic-pituitary-adrenal stress reactivity and Fos induction in the rat locus coeruleus in response to subsequent immobilization stress. Neuroscience. 2008 Jul 17:1639-47.

Machado BH. Neurotransmission of the cardiovascular reflexes in the nucleus tractus solitarii of awake rats. Ann N Y Acad Sci. 2001 Jun:179-96.

Malpas SC. The rhythmicity of sympathetic nerve activity. Prog Neurobiol. 1998 Oct:65-96.

Malpas SC. Sympathetic nervous system overactivity and its role in the development of cardiovascular disease. Physiol Rev. 2010 Apr:513-57.

Moraes DJ, Zoccal DB, Machado BH. Medullary respiratory network drives sympathetic overactivity and hypertension in rats submitted to chronic intermittent hypoxia. Hypertension. 2012 Dec:1374-80.

Mortola JP, Saiki C. Ventilatory response to hypoxia in rats: gender differences. Respir Physiol. 1996 Oct:21-34.

Ouchi Y, Share L, Crofton JT, Iitake K, Brooks DP. Sex difference in the development of deoxycorticosterone-salt hypertension in the rat. Hypertension. 1987 Feb:172-7.

Patel KP, Li YF, Hirooka Y. Role of nitric oxide in central sympathetic outflow. Exp Biol Med (Maywood). 2001 Oct:814-24.

Pawar A, Peng YJ, Jacono FJ, Prabhakar NR. Comparative analysis of neonatal and adult rat carotid body responses to chronic intermittent hypoxia. J Appl Physiol. 2008 May:1287-94.

Peng YJ, Rennison J, Prabhakar NR. Intermittent hypoxia augments carotid body and ventilatory response to hypoxia in neonatal rat pups. J Appl Physiol. 2004 Nov:2020-5.

Poletini MO, Szawka RE, Freitas Marcon RM, Veiga MD, Franci CR, AnselmoFranci JA. A method to study preovulatory surges of gonadotropins. Brain Res Brain Res Protoc. 2003 Aug:41-8.

Reckelhoff JF. Basic research into the mechanisms responsible for postmenopausal hypertension. Int J Clin Pract Suppl. 2004 Mar:13-9.

Reckelhoff JF. Gender differences in the regulation of blood pressure. Hypertension. 2001 May:1199-208. 
Reckelhoff JF, Zhang H, Granger JP. Testosterone exacerbates hypertension and reduces pressure-natriuresis in male spontaneously hypertensive rats. Hypertension. 1998 Jan:435-9.

Reckelhoff JF, Zhang H, Srivastava K, Granger JP. Gender differences in hypertension in spontaneously hypertensive rats: role of androgens and androgen receptor. Hypertension. 1999 Oct:920-3.

Reeves SR, Gozal D. Developmental plasticity of respiratory control following intermittent hypoxia. Respir Physiol Neurobiol. 2005 Nov 15:301-11.

Rowland NE, Fregly MJ. Role of gonadal hormones in hypertension in the Dahl saltsensitive rat. Clin Exp Hypertens A. 1992:367-75.

Simms AE, Paton JF, Allen AM, Pickering AE. Is augmented central respiratorysympathetic coupling involved in the generation of hypertension? Respir Physiol Neurobiol. 2010 Nov 30:89-97.

Simms AE, Paton JF, Pickering AE, Allen AM. Amplified respiratory-sympathetic coupling in the spontaneously hypertensive rat: does it contribute to hypertension? J Physiol. 2009 Feb 1:597-610.

Skelly JR, Edge D, Shortt CM, Jones JF, Bradford A, O'Halloran KD. Tempol ameliorates pharyngeal dilator muscle dysfunction in a rodent model of chronic intermittent hypoxia. Am J Respir Cell Mol Biol. 2011 Feb:139-48.

Somers VK, Dyken ME, Clary MP, Abboud FM. Sympathetic neural mechanisms in obstructive sleep apnea. J Clin Invest. 1995 Oct:1897-904.

Takezawa H, Hayashi H, Sano H, Saito H, Ebihara S. Circadian and estrous cycledependent variations in blood pressure and heart rate in female rats. Am $\mathbf{J}$ Physiol. 1994 Nov:R1250-6.

Tatsumi K, Hannhart B, Pickett CK, Weil JV, Moore LG. Influences of gender and sex hormones on hypoxic ventilatory response in cats. J Appl Physiol. 1991 Nov:1746-51.

ter Horst JP, de Kloet ER, Schachinger H, Oitzl MS. Relevance of stress and female sex hormones for emotion and cognition. Cell Mol Neurobiol. 2012 Jul:725-35.

Thomas GD. Neural control of the circulation. Adv Physiol Educ. 2011 Mar:28-32.

Toney GM, Pedrino GR, Fink GD, Osborn JW. Does enhanced respiratorysympathetic coupling contribute to peripheral neural mechanisms of angiotensin II-salt hypertension? Exp Physiol. 2010 May:587-94.

Traslavina GA, Franci CR. The CRH-R(1) receptor mediates luteinizing hormone, prolactin, corticosterone and progesterone secretion induced by restraint stress in estrogen-primed rats. Brain Res. 2011 Nov 3:11-9.

Trinder J, Kay A, Kleiman J, Dunai J. Gender differences in airway resistance during sleep. J Appl Physiol. 1997 Dec:1986-97. 
Viau V, Bingham B, Davis J, Lee P, Wong M. Gender and puberty interact on the stress-induced activation of parvocellular neurosecretory neurons and corticotropin-releasing hormone messenger ribonucleic acid expression in the rat. Endocrinology. 2005 Jan:137-46.

Wang G, Milner TA, Speth RC, Gore AC, Wu D, Iadecola C, et al. Sex differences in angiotensin signaling in bulbospinal neurons in the rat rostral ventrolateral medulla. Am J Physiol Regul Integr Comp Physiol. 2008 Oct:R1149-57.

Wenninger JM, Olson EB, Jr., Cotter CJ, Thomas CF, Behan M. Hypoxic and hypercapnic ventilatory responses in aging male vs. aging female rats. $\boldsymbol{J} \boldsymbol{A p p l}$ Physiol. 2009 May:1522-8.

Xue B, Johnson AK, Hay M. Sex differences in angiotensin II- induced hypertension. Braz J Med Biol Res. 2007 May:727-34.

Xue B, Pamidimukkala J, Hay M. Sex differences in the development of angiotensin IIinduced hypertension in conscious mice. Am J Physiol Heart Circ Physiol. 2005 May:H2177-84.

Xue B, Singh M, Guo F, Hay M, Johnson AK. Protective actions of estrogen on angiotensin II-induced hypertension: role of central nitric oxide. Am J Physiol Heart Circ Physiol. 2009 Nov:H1638-46.

Zabka AG, Behan M, Mitchell GS. Selected contribution: Time-dependent hypoxic respiratory responses in female rats are influenced by age and by the estrus cycle. J Appl Physiol. 2001 Dec:2831-8.

Zapatero-Caballero H, Sanchez-Franco F, Guerra-Perez N, Fernandez-Mendez C, Fernandez-Vazquez G. Gonadotropin-releasing hormone receptor gene expression during pubertal development of male rats. Biol Reprod. 2003 May:1764-70.

Zoccal DB, Bonagamba LG, Antunes-Rodrigues J, Machado BH. Plasma corticosterone levels is elevated in rats submitted to chronic intermittent hypoxia. Auton Neurosci. 2007a Jul 31:115-7.

Zoccal DB, Bonagamba LG, Oliveira FR, Antunes-Rodrigues J, Machado BH. Increased sympathetic activity in rats submitted to chronic intermittent hypoxia. Exp Physiol. 2007b Jan:79-85.

Zoccal DB, Bonagamba LG, Paton JF, Machado BH. Sympathetic-mediated hypertension of awake juvenile rats submitted to chronic intermittent hypoxia is not linked to baroreflex dysfunction. Exp Physiol. 2009a Sep:972-83.

Zoccal DB, Machado BH. Coupling between respiratory and sympathetic activities as a novel mechanism underpinning neurogenic hypertension. Curr Hypertens Rep. 2011 Jun:229-36. 
Zoccal DB, Paton JF, Machado BH. Do changes in the coupling between respiratory and sympathetic activities contribute to neurogenic hypertension? Clin Exp Pharmacol Physiol. 2009b Dec:1188-96.

Zoccal DB, Simms AE, Bonagamba LG, Braga VA, Pickering AE, Paton JF, et al. Increased sympathetic outflow in juvenile rats submitted to chronic intermittent hypoxia correlates with enhanced expiratory activity. J Physiol. 2008 Jul 1:325365. 